\title{
Reducing structural uncertainty in conceptual hydrological modelling in the semi-arid Andes
}

\author{
P. Hublart ${ }^{1,4}$, D. Ruelland ${ }^{2}$, A. Dezetter ${ }^{3}$, and H. Jourde ${ }^{1}$ \\ ${ }^{1}$ UM2 - UMR HydroSciences Montpellier, Place E. Bataillon, 34395 Montpellier CEDEX 5, France \\ ${ }^{2}$ CNRS - UMR HydroSciences Montpellier, Place E. Bataillon, 34395 Montpellier CEDEX 5, France \\ ${ }^{3}$ IRD - UMR HydroSciences Montpellier, Place E. Bataillon, 34395 Montpellier CEDEX 5, France \\ ${ }^{4}$ Centro de Estudios Avanzados en Zonas Áridas (CEAZA), Raúl Bitrán s/n, La Serena, Chile \\ Correspondence to: P. Hublart (paul.hublart@um2.fr) and D. Ruelland (denis.ruelland@um2.fr)
}

Received: 14 August 2014 - Published in Hydrol. Earth Syst. Sci. Discuss.: 31 October 2014

Revised: 16 March 2015 - Accepted: 15 April 2015 - Published: 13 May 2015

\begin{abstract}
The use of lumped, conceptual models in hydrological impact studies requires placing more emphasis on the uncertainty arising from deficiencies and/or ambiguities in the model structure. This study provides an opportunity to combine a multiple-hypothesis framework with a multicriteria assessment scheme to reduce structural uncertainty in the conceptual modelling of a mesoscale Andean catchment $\left(1515 \mathrm{~km}^{2}\right)$ over a 30-year period (1982-2011). The modelling process was decomposed into six model-building decisions related to the following aspects of the system behaviour: snow accumulation and melt, runoff generation, redistribution and delay of water fluxes, and natural storage effects. Each of these decisions was provided with a set of alternative modelling options, resulting in a total of 72 competing model structures. These structures were calibrated using the concept of Pareto optimality with three criteria pertaining to streamflow simulations and one to the seasonal dynamics of snow processes. The results were analyzed in the fourdimensional (4-D) space of performance measures using a fuzzy c-means clustering technique and a differential split sample test, leading to identify 14 equally acceptable model hypotheses. A filtering approach was then applied to these best-performing structures in order to minimize the overall uncertainty envelope while maximizing the number of enclosed observations. This led to retain eight model hypotheses as a representation of the minimum structural uncertainty that could be obtained with this modelling framework. Future work to better consider model predictive uncertainty should include a proper assessment of parameter equifinality and
\end{abstract}

data errors, as well as the testing of new or refined hypotheses to allow for the use of additional auxiliary observations.

\section{Introduction}

Conceptual catchment models based on the combination of several interconnected stores are popular tools in flood forecasting and water resources management (e.g. Jakeman and Letcher, 2003; Xu and Singh, 2004). The main rationale behind this success lies in the fact that relatively simple structures with low data and computer requirements generally outweigh the performance of far more complex physically based models (e.g. Michaud and Sorooshian, 1994; Refsgaard and Knudsen, 1996; Kokkonen and Jakeman, 2001). Also, most water management decisions are made at operational scales having much more to do with catchment-scale administrative considerations than with our understanding of fine-scale processes. As a result, conceptual models are being increasingly used to evaluate the potential impacts of climate change on hydrological systems (e.g. Minville et al., 2008; Ruelland et al., 2012) and freshwater availability (e.g. Milano et al., 2013; Collet et al., 2013).

This modelling strategy, however, is regularly criticized for oversimplifying the physics of catchments and leading to unreliable simulations when conditions shift beyond the range of prior experience. Part of the problem comes from the fact that model structures are usually specified a priori, based on preconceived opinions about how systems work, which in general leads to an excessive dependence on the calibra- 
tion process. More than a lack of physical background, this practice reveals a misunderstanding about how such models should be based on physics (Kirchner, 2006; Blöschl and Montanari, 2010). Hydrological systems are not structureless things composed of randomly distributed elements, but rather self-organizing systems characterized by the emergence of macroscale patterns and structures (Dooge, 1986; Sivapalan, 2005; Ehret et al., 2014). As such, the reductionist idea that catchments can be understood by merely aggregating (upscaling) fine-scale mechanistic laws is generally misleading (Dooge, 1997; McDonnell et al., 2007). Self-organization at the catchment scale means that new hydrologic relationships with fewer degrees of freedom have to be envisioned (e.g. McMillan, 2012a). Yet, finding simplicity in complexity does not imply that simple models available in the literature can be used as ready-made engineering tools with little or no consideration for the specific features of each catchment (Wainwright and Mulligan, 2004; Savenije, 2009). As underlined by Kirchner (2006), it is important to ensure that the "right answers" are obtained for the "right reasons". In the case of poorly defined systems where physically oriented interpretations can only be sought a posteriori to check for the model realism, this requires placing more emphasis on the uncertainty arising from deficiencies and/or ambiguities in the model structure than is currently done in most hydrological impact studies.

Structural uncertainty can be described in terms of inadequacy and non-uniqueness. Model inadequacy arises from the many simplifying assumptions and epistemic errors made in the selection of which processes to represent and how to represent them. It reflects the extent to which a given model differs from the real system it is intended to represent. In practice, this results in the failure to capture all relevant aspects of the system behaviour within a single model structure or parameter set. A common way of addressing this source of uncertainty is to adopt a top-down approach to model-building (Jothityangkoon et al., 2001; Sivapalan et al., 2003), in which different models of increasing complexity are tested to determine the adequate level of process representation. Where fluxes and state variables are made explicit, alternative data sources (other than streamflow) such as groundwater levels (Seibert, 2000; Seibert and McDonnell, 2002), tracer samples (Son and Sivapalan, 2007; Birkel et al., 2010; Capell et al., 2012) or snow measurements (Clark et al., 2006; Parajka and Blöschl, 2008), can also be used to improve the internal consistency of model structures. Additional criteria can then be introduced in relation to these auxiliary data or to specific aspects of the hydrograph (driven vs. non-driven components, rising limb, recession limbs, etc.). In this perspective, multi-criteria evaluation techniques based on the concept of Pareto-optimality provide an interesting way to both reduce and quantify structural inadequacy (Gupta et al., 1998; Boyle et al., 2000; Efstratiadis and Koutsoyiannis, 2010). A parameter set is said to be Pareto-optimal if it cannot be improved upon without degrad- ing at least one of the objective criteria. In general, meaningful information on the origin of model deficiencies can be derived from the mapping of Pareto-optimal solutions in the space of performance measures (often called the Pareto front) and used to discriminate between several rival structures (Lee et al., 2011). Further, the Pareto set of solutions obtained with a given model is commonly used to generate simulation envelopes (hereafter called "Pareto-envelopes" for the sake of brevity) representing the uncertainty associated with structural errors (i.e. model inadequacy).

Non-uniqueness refers to the existence of many different model structures (and parameter sets) giving equally acceptable fits to the observed data. Structural inadequacy and the limited (and often uncertain) information of the available data make it highly unlikely to identify a single, unambiguous representation of how a system works. There may be, for instance, many different possible representations of flow pathways yielding the same integral signal (e.g. streamflow) at the catchment outlet (Schaefli et al., 2011). Nonuniqueness in model identification has also been widely described in terms of equifinality (Beven, 1993, 2006) and may be viewed as a special case of a more general epistemological issue known as the "underdetermination" problem. Over the past decade, these considerations have encouraged a shift in focus toward more flexible modelling tools based on the concept of multiple working hypotheses (Buytaert and Beven, 2011; Clark et al., 2011). A number of modular frameworks have been proposed, in which model components (i.e. individual hypotheses) can be assembled and connected in many ways to build a variety of alternative model structures (i.e. overall hypotheses). Recent examples of such modular modelling frameworks (MMFs) include the Imperial College Rainfall-Runoff Modelling Toolbox (RRMT) (Wagener et al., 2002), the Framework for Understanding Structural Errors (FUSE) (Clark et al., 2008) and the SUPERFLEX modelling environment (Fenicia et al., 2011). Clark et al. (2011) suggested that this approach to model identification represents a valuable alternative to "most practical applications of the top-down approach", which "seldom consider competing process representations of equivalent complexity". Compared to current multimodel strategies, MMFs also provide the possibility to better scrutinize the effect of each individual hypothesis (i.e. model component), provided that the model decomposition is sufficiently fine-grained. Finally, Clark et al. (2011) argued that ensembles of competing model structures obtained from MMFs (both of equal and varying complexity) can also be used to quantify the structural uncertainty arising because of system non-identifiability (i.e. model non-uniqueness). So far, however, this method has mostly been applied to relatively small $\left(<500 \mathrm{~km}^{2}\right)$ and humid catchments of the Northern Hemisphere (Krueger et al., 2010; Smith and Marshall, 2010; Staudinger et al., 2011; Kavetski and Fenicia, 2011; McMillan et al., 2012b; Coxon et al., 2013), with less attention being given to larger scales of interest $\left(>1000 \mathrm{~km}^{2}\right)$ and semi- 

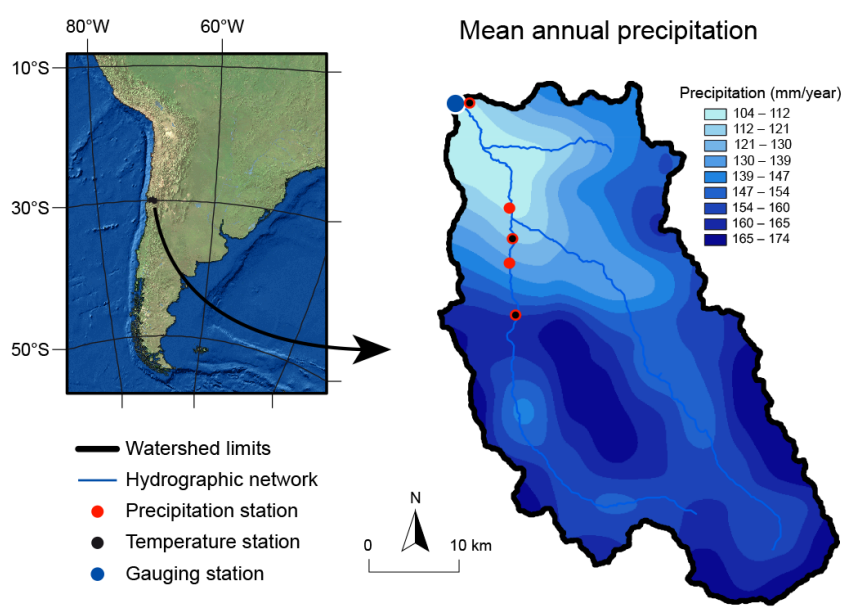

Digital Elevation Model

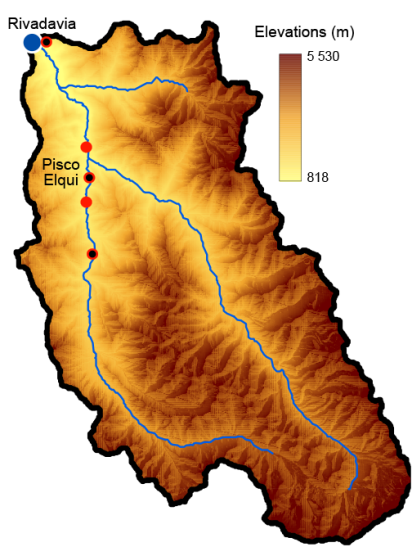

Mean annual temperature

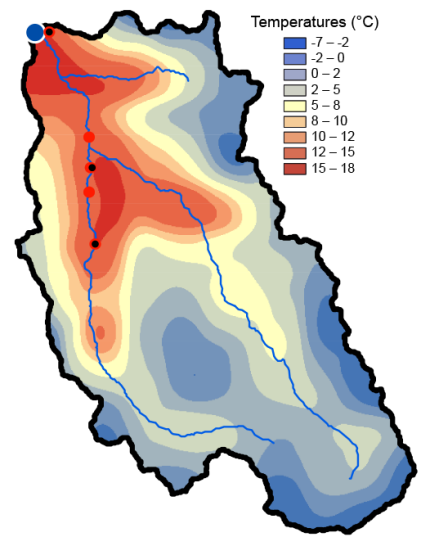

Figure 1. The Claro River basin at Rivadavia $\left(1515 \mathrm{~km}^{2}\right)$ in Chile: topography and mean annual precipitation and temperature from 1982 to 2011 (based on Ruelland et al., 2014). Several of the stations used in this study were located outside the catchment and therefore are not displayed on the following maps.

arid regions (e.g. Clark et al., 2008). Moreover, several of these studies have insisted on the need for multiple criteria related to different aspects of the system's behaviour in order to improve the usefulness of MMFs. Yet, most of the time these additional criteria or signatures were not used to guide model development or constrain calibration but rather as posterior diagnostics in validation (see Kavetski and Fenicia, 2011). Thus, the potential benefits of using the concept of Pareto-efficiency to constrain model development and help differentiate between numerous competing hypotheses remain largely unexplored in the current literature devoted to MMFs. Also, very few studies have included alternative conceptual representations of snow processes in their modular frameworks (e.g. Smith and Marshall, 2010), even though snowmelt may have played a significant role in several cases (Clark et al., 2008; Staudinger et al., 2011).

Addressing these issues is of particular importance in the case of arid to semi-arid Andean catchments such as those found around $30^{\circ} \mathrm{S}$. The Norte Chico region of Chile, in particular, has been identified as being highly vulnerable to climate change impacts in a number of recent reports (IPCC, 2013) and studies (e.g. Souvignet et al., 2010; Young et al., 2010). Yet, very few catchments in this region have been studied intensively enough to provide reliable model simulations, often with no estimation of the surrounding uncertainty (Souvignet, 2007; Ruelland et al., 2011; Vicuña et al., 2011; Hublart et al., 2013). This study is the first step of a larger research project, whose final aim is to assess the capacity to meet current and future irrigation water requirements in a mesoscale catchment of the Norte Chico region. The objective here is to provide a set of reasonable model structures that can be used for the hydrological modelling of the catchment. To achieve this goal, a MMF was developed and combined with a multi-criteria optimization framework using streamflow and satellite-based snow cover data.

\section{Study area}

\subsection{General site description}

The Claro River catchment is a semi-arid, mountainous catchment located in the northeastern part of the Coquimbo region, in north-central Chile (Fig. 1). It drains an area of approximately $1515 \mathrm{~km}^{2}$, characterized by high elevations ranging from $820 \mathrm{~m}$ a.s.l. at the basin outlet (Rivadavia) to over $5500 \mathrm{~m}$ a.s.l. in the Andes Cordillera. The topography is dominated by a series of generally north-trending, faultbounded mountain blocks interspersed with a few steepsided valleys.

The underlying bedrock consists almost entirely of granitic rocks ranging in age from Pennsylvanian to Oligocene and locally weathered to saprolite. Above $3000 \mathrm{~m}$, repeated glaciations and the continuous action of frost and thaw throughout the year have caused an intense shattering of the exposed rocks (Caviedes and Paskoff, 1975), leaving a landscape of bare rock and screes almost devoid of soil.

The valley-fill material consists of mostly unconsolidated Quaternary alluvial sediments mantled by generally thin soils $(<1 \mathrm{~m})$ of sandy to sandy loam texture. Vineyards and orchards cover most of the valley floors and lower hill slopes but account for less than $1 \%$ of the total catchment area. Most of the annual precipitation, however, occurs as snow during the winter months, leading to an entire dependence on surface-water resources to satisfy crop water needs during the summer. Irrigation water abstractions occur at multiple locations along the river's course depending on both historical water rights and water availability. By contrast, natural vegetation outside the valleys is extremely sparse and composed mainly of subshrubs (e.g. Adesmia echinus and cushion plants (e.g. Laretia acaulis, Azorella compacta) with very low transpiration rates (Squeo et al., 1993). The Claro River 
originates from a number of small tributaries flowing either permanently or seasonally in the mountains.

\subsection{Hydro-climatic data}

In order to represent the hydro-climatic variability of the catchment, a 30-year period (1982-2011) was chosen according to data availability and quality. Precipitation and temperature data were interpolated based on 12 and 8 stations, respectively (Fig. 1), using the inverse distance weighted method on a $5 \mathrm{~km} \times 5 \mathrm{~km}$ grid. Since very few measurements were available outside the river valleys, elevation effects on precipitation and temperature distribution were considered using the Shuttle Radar Topography Mission digital elevation model (Fig. 1). In a previous study, Ruelland et al. (2014) examined the sensitivity of the GR4j hydrological model to different ways of interpolating climate forcing on this basin. Their results showed that a data set based on a constant lapse rate of $6.5^{\circ} \mathrm{C} \mathrm{km}^{-1}$ for temperature and no elevation effects for precipitation provided slightly better simulations of the discharge over the last 30 years. However, since the current study also seeks to reproduce the seasonal dynamics of snow accumulation and melt, it was decided to rely on a mean monthly orographic gradient estimated from the precipitation observed series (Fig. 1). Potential evapotranspiration (PE) was computed using the following formula proposed by Oudin et al. (2005):

$\mathrm{PE}=\frac{\mathrm{R}_{\mathrm{e}}}{\lambda \rho} \cdot \frac{\mathrm{T}+K_{2}}{K_{1}}$ if $\mathrm{T}+K_{2}>0$ else $\mathrm{PE}=0$,

where $\mathrm{PE}$ is the rate of potential evapotranspiration $\left(\mathrm{mm} \mathrm{d}^{-1}\right), \mathrm{R}_{\mathrm{e}}$ is the extraterrestrial radiation $\left(\mathrm{MJ} \mathrm{m}^{-2} \mathrm{~d}^{-1}\right)$, $\lambda$ is the latent heat flux $\left(2.45 \mathrm{MJ} \mathrm{kg}^{-1}\right), \rho$ is the density of water $\left(\mathrm{kg} \mathrm{m}^{-3}\right)$, T is the mean daily air temperature $\left({ }^{\circ} \mathrm{C}\right)$ and $K_{1}$ and $K_{2}$ are fitted parameters (for more details on the values of $K_{1}$ and $K_{2}$, see Hublart et al., 2014). Water abstractions for irrigation were estimated using information on historical water allocations provided by the Chilean authorities. Because these abstractions are likely to influence the hydrological behaviour of the catchment during recession and low-flow periods, they were added back to the gauged streamflow in Rivadavia before calibrating the models. In addition to streamflow data, remotely sensed data from the moderate resolution imaging spectroradiometer (MODIS) sensor were used to estimate the seasonal dynamics of snow accumulation and melt processes over a 9-year period (2003-2011). Daily snow cover products retrieved from NASA's Terra (MOD10A1) and Aqua (MYD10A1) satellites were combined into a single, composite $500 \mathrm{~m}$ resolution product to reduce the effect of swath gaps and cloud obscuration. The remaining data voids were subsequently filled using a linear temporal interpolation method.

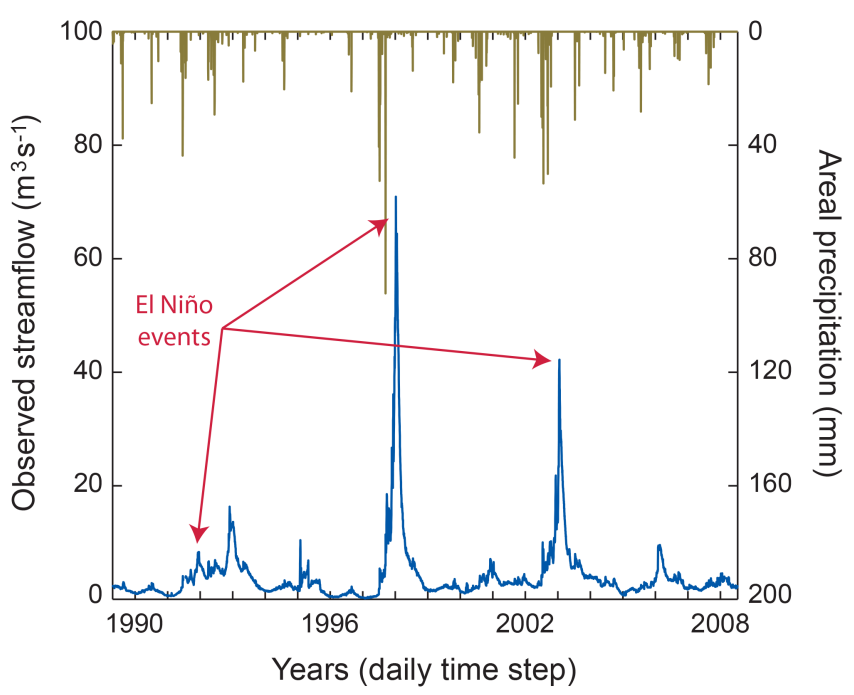

Figure 2. Interannual variability in precipitation and observed streamflow from 1989 to 2008 . The hydrological year was defined from May to April so as to capture the snowmelt and peak flow seasons at mid-year (the graduations on the $x$ axis indicate the 1 January of each year). Streamflow values are those measured at the catchment outlet before accounting for water abstractions. Precipitation values are those obtained after interpolation.

\subsection{Hydrological functioning of the catchment}

\subsubsection{Precipitation variability}

Among the primary factors that control the hydrological functioning of the catchment is the high seasonality of precipitation patterns. Precipitation occurs mainly between June and August when the South Pacific high reaches its northernmost position. Most of the annual precipitation falls as snow at high elevations, where it accumulates in seasonal snowpack that are gradually released from October to April. The El Niño-Southern Oscillation (ENSO) represents the largest source of climate variability at the interannual timescale (e.g. Montecinos and Aceituno, 2003) (Fig. 2). Anomalously wet (dry) years in the region are generally associated with warm (cold) El Niño (La Niña) episodes and a simultaneous weakening (strengthening) of the South Pacific high. It is worth noting, however, that some very wet years in the catchment can also coincide with neutral to weak La Niña conditions, as in 1984, while several years of below-normal precipitation may not exhibit clear La Niña characteristics (Verbist et al., 2010; Jourde et al., 2011). These anomalies may be due to other modes of climate variability affecting the Pacific basin on longer timescales. The Interdecadal Pacific Oscillation (IPO), in particular, has been shown to modulate the influence of ENSO-related events according to cycles of between 15 and 30 years (Quintana and Aceituno, 2012). Recent shifts in the IPO phase occurred in 1977 and 1998 and may be responsible for the highest frequency of humid years 
during the 1980s and the early 1990 s when compared to the late 1990 s and the 2000s.

\subsubsection{Catchment-scale water balance and dominant processes}

Notwithstanding this significant climate variability, a rough estimate of the catchment water balance can be given for the period 2003-2011 using the data presented in the previous subsection and additional information available in the literature. Spatially averaged precipitation ranges from a minimum of $80 \mathrm{~mm}$ in 2010 to an estimated maximum of $190 \mathrm{~mm}$ in 2008. Evapotranspiration from non-cultivated areas is sufficiently low to be reasonably neglected at the basin scale (Kalthoff et al., 2006). By contrast, water losses from the cultivated portions of the basin are likely to be around $10 \mathrm{~mm} \mathrm{yr}^{-1}$ (Hublart et al., 2014). At high elevations, sublimation plays a much greater role than evapotranspiration. Mean annual sublimation rates over two glaciers located in similar, neighbouring catchments have been estimated to be about $1 \mathrm{~mm} \mathrm{~d}^{-1}$ (see, e.g., MacDonell et al., 2013). Thus, a first estimate of the annual water loss associated with snow sublimation can be made by multiplying, for each day of the period, the proportion of the catchment covered with snow by an average rate of $1 \mathrm{~mm} \mathrm{~d}^{-1}$. This leads to a mean annual loss of $70 \mathrm{~mm}$ between 2003 and 2011. Note that this value is of the same order of magnitude as those obtained by Favier et al. (2009) using the Weather Research and Forecasting regional-scale climate model. Mean annual discharge per unit area varies from a minimum of $20 \mathrm{~mm}$ in 2010 to a maximum of $140 \mathrm{~mm}$ in 2003. Interestingly, runoff coefficients exceed $100 \%$ during several years in this period (in 2003, 2006, 2007 and 2009), indicating either an underestimation of precipitation at high elevations, as suggested by Favier et al. (2009), or a delayed contribution of groundwater to surface flow from one year to another (Jourde et al., 2011).

Groundwater movement in the catchment is mainly from the mountain blocks toward the valleys and then northward along the riverbed. In the mountains, groundwater flow and storage are controlled primarily by the presence of secondary permeability in the form of joints and fractures (Strauch et al., 2006). The unconfined valley-fill aquifers are replenished by mountain front recharge along the valley margins and by infiltration through the channel bed along the losing river reaches (Jourde et al., 2011). Their hydraulic conductivity and saturated thickness range from about $10 \mathrm{~m} \mathrm{~d}^{-1}$ and $40 \mathrm{~m}$, respectively, in the upper part of the catchment to more than $30 \mathrm{~m} \mathrm{~d}^{-1}$ and $60 \mathrm{~m}$ respectively at the outlet (CAZALAC, 2006), allowing a rapid transfer of water to the hydraulically connected surface streams. Pourrier et al. (2014) studied flow processes and dynamics in the headwaters of the neighbouring Turbio River catchment; yet very little remains currently known about the emergent processes taking place at the catchment scale.

\section{Methods}

\subsection{Multiple-hypothesis modelling framework}

In order to evaluate various numerical representations of the catchment functioning, a multiple-hypothesis modelling framework inspired by previous studies in literature was developed. All the models built within this framework are lumped hypotheses run at a daily time step. The modelling process was decomposed into three modules and six modelbuilding decisions. Each module deals with a different aspect of the precipitation-runoff relationship through one or more decisions (Fig. 3): snow accumulation (A) and melt (B), runoff generation $(\mathrm{C})$, redistribution $(\mathrm{D})$ and delay $(\mathrm{E})$ of water fluxes, and natural storage effects $(F)$. Each of these decisions is provided with a set of alternative modelling options, which are named by concatenating the following elements: first a capital letter from A to F referring to the decision being addressed, then a number from 1 to 3 to distinguish between several competing architectures and, finally, a lower case letter from $a$ to $c$ to indicate different parameterizations of the same architecture. Model hypotheses are named by concatenating the names of the six modelling options used to build them (see Table 4). The models designed within this framework share the same overall structure (based on the same series of decisions) but differ in their specific formulations within each decision.

The model-building decisions can be divided into two broad categories. The first pertains to the production of fluxes from conceptual stores (decisions B, C and F). The second concerns the allocation and transmission of these fluxes using the typical junction elements and lag functions (decisions A, D and E) described in Fenicia et al. (2011). Junction elements can be defined as "zero-state" model components used to combine several fluxes into a single one (option D2) or split a single flux into two or more fluxes (options A1 and D3). Lag functions are used to reflect the travel time (delay) required to convey water from one conceptual store to another or from one or more conceptual stores to the basin outlet. They usually consist of convolution operators (option E2), although conceptual stores may also do the trick. Modelling options in which water fluxes are left unchanged are labelled as "No operation" options in Fig. 3. Water fluxes and state variables are named using generic names (from Q1 to Q6 and from S1 to S4, respectively) to ensure a perfect modularity of the framework. Further details on the alternative options provided for each decision are given in the following subsections. Note that some combinations of modelling options were clearly incompatible with one another (options C1 and $\mathrm{C} 2$, for instance, cannot work with option D2). As a result, these combinations were removed from the framework.

Another important feature of this modular framework is the systematic smoothing of all model thresholds using infinitely differentiable approximants, as recommended by Kavetski and Kuczera (2007) and Fenicia et al. (2011). The 


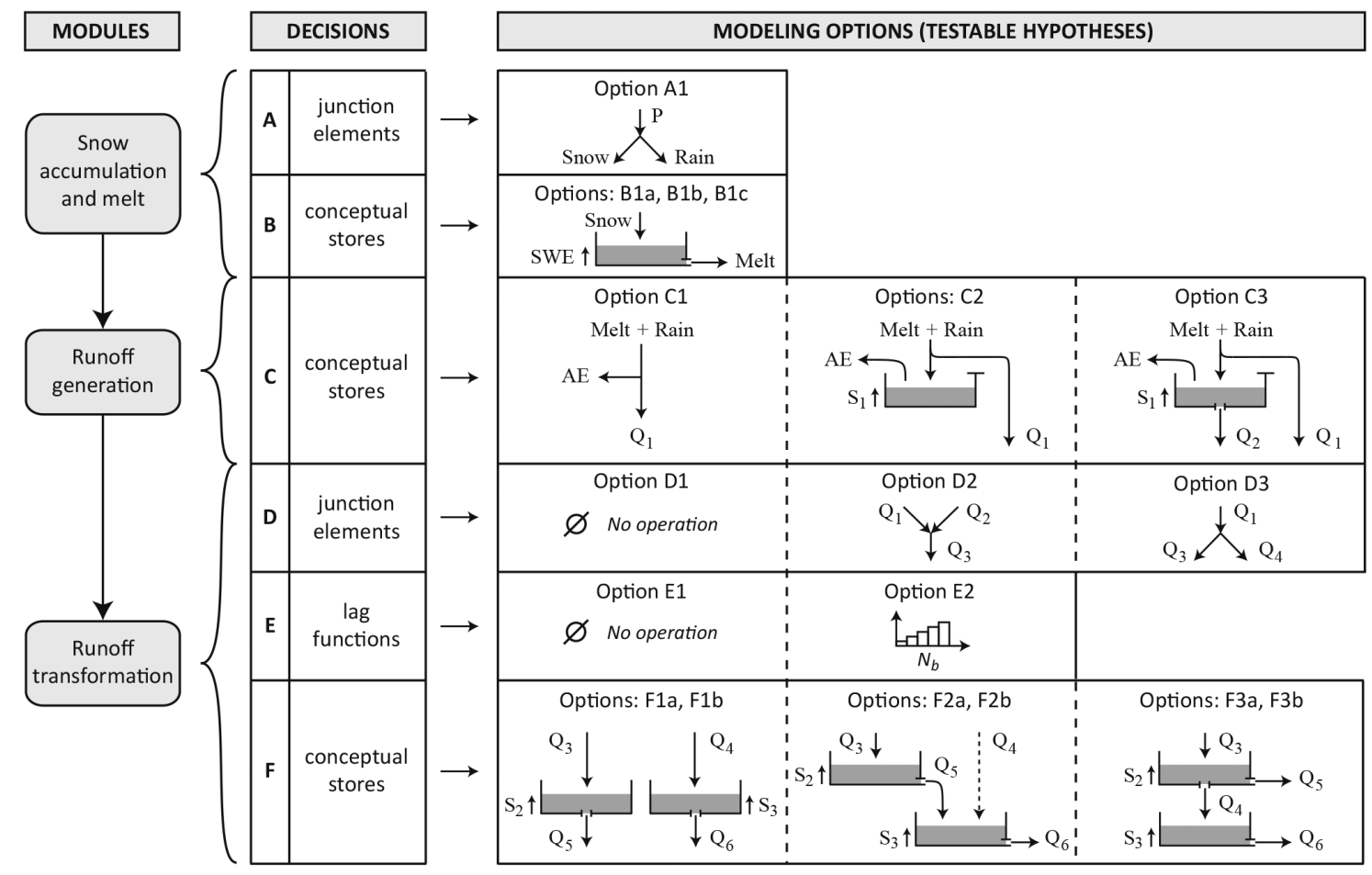

Figure 3. Overall architecture (modules), decision tree and available modelling options of the modular multiple-hypothesis framework (P: catchment-averaged daily precipitation; $\mathrm{SWE}$ : snow water equivalent; $\mathrm{AE}$ : catchment-averaged daily actual evapotranspiration; $\mathrm{S}_{\mathrm{j}} j \in[1,5]$ : state variables of the conceptual stores; $\mathrm{Q}_{\mathrm{j}} j \in[1,5]$ : water fluxes between the model components).

purpose here is twofold: first, to facilitate the calibration process by removing any unnecessary (and potentially detrimental) discontinuities from the gradients of the objective functions; and second, to provide a more realistic description of hydrological processes across the catchment (Moore, 2007).

\subsubsection{Snow accumulation and melt (decisions $A$ and $B$ )}

Snow accumulation and melt components deal with the representation of snow processes at the catchment scale. All modelling options rely on a single conceptual store to accumulate snow during the winter months and release water during the melt season. Decision A refers to the partitioning of precipitation into rain, snow or a mixture of rain and snow. Decision B refers to the representation of snowmelt processes. Option A1 is the only hypothesis implemented to evaluate the relative abundance of rain and snow. A logistic distribution is used in this option instead of usual temperature thresholds to implicitly account for spatial variations in rain/snow partitioning over the catchment. In contrast, three modelling options drawing upon the temperatureindex approach (Hock, 2003) are available for the evaluation of snowmelt rates (options B1a, B 1b, B1c). Option B1a relies on a constant melt factor while options B1b and B1c allow for temporal variability in the melt factor to reflect seasonal changes in the energy available for melt. A recent example of option B1c can be found in Clark et al. (2009). Option B1b has been previously applied by Schreider et al. (1997) but at the grid cell scale. Finally, it is worth noting that a smoothing kernel proposed by Kavetski and Kuczera (2007) was introduced in the state equation of the snow reservoir to ignore residual snow remaining in the reservoir outside the snowmelt season.

\subsubsection{Runoff generation (decision C)}

Runoff generation components determine how much of a rainfall or snowmelt event is available for runoff, lost through evapotranspiration or temporarily stored in soils and surface depressions. Many models rely on a conceptual store to keep track of the catchment moisture status and generate runoff as a function of both current and antecedent precipitation. Here, an assortment of four commonly used methods is available. Option $\mathrm{C} 1$ is the only one in which no moistureaccounting store is required to estimate the contributing rainfall or snowmelt (see Fig. 3). Actual evapotranspiration then represents the only process involved in the production of runoff from precipitation or snowmelt. The remaining options make use of moisture-accounting stores and distribution functions (see Table 1) to estimate the proportion of the basin generating runoff. An important distinction is made between option $\mathrm{C} 2$, in which runoff generation occurs only dur- 
Table 1. Constitutive equations of fluxes between the various components of the modelling options described in Fig. 2. Parameter (in italic) significations and units are detailed in Table 2 (P: catchment-averaged daily precipitation; rain: rain fraction of precipitation P; snow: snow fraction of precipitation P; T: catchment-averaged daily temperature; PE: catchment-averaged daily potential evapotranspiration; AE: catchment-averaged daily actual evapotranspiration; $S_{j}, j \in[1,5]$ : state variables of the conceptual stores; $Q_{j}, j \in[1,5]$ : water fluxes between the model components).

\begin{tabular}{|c|c|c|c|}
\hline Options & Constitutive equations & Options & Constitutive equations \\
\hline A1 & $\begin{array}{l}\text { Snow }=\mathrm{P} /\left(1+\exp \left[\left(T-T_{\mathrm{S}}\right) / m_{\mathrm{S}}\right]\right) \\
\text { Rain }=\mathrm{P}-\text { Snow }\end{array}$ & $\mathrm{C} 3$ & $\begin{array}{l}\mathrm{Q}_{1}=(\text { Melt }+ \text { Rain })\left[1-\left(1-S_{1} / S_{\mathrm{m}}\right)^{b}\right] \\
\mathrm{Q}_{2}=K_{1} \mathrm{~S}_{1}\end{array}$ \\
\hline $\begin{array}{l}\text { B1a, B1b, } \\
\text { B1c }\end{array}$ & $\begin{array}{l}\text { Melt }=\operatorname{MF}(\overline{\mathrm{T}}-\log [1+\exp (-\bar{T})]) \\
\text { with } \overline{\mathrm{T}}=\left(\mathrm{T}-T_{\mathrm{M}}\right) / \mathrm{m}_{\mathrm{M}} \text { and } \mathrm{m}_{\mathrm{M}}=0.1^{\circ} \mathrm{C}\end{array}$ & D1 & $\begin{array}{l}\mathrm{Q}_{3}=\mathrm{Q}_{2} \text { and } \mathrm{Q}_{4}=\mathrm{Q}_{1} \\
\text { or } \mathrm{Q}_{3}=\mathrm{Q}_{1}\end{array}$ \\
\hline B1a & $\mathrm{MF}=f_{\mathrm{M}} \mathrm{m}_{\mathrm{M}}$ & D2 & $\mathrm{Q}_{3}=\mathrm{Q}_{1}+\mathrm{Q}_{2}$ \\
\hline B1b & $\begin{array}{l}\mathrm{MF}=r_{1}+r_{2} \mathrm{~T}_{30} \\
\text { with } \mathrm{T}_{30} \text { the mean temperature of } \\
\text { the last } 30 \text { days }\end{array}$ & D3 & $\begin{array}{l}\mathrm{Q}_{3}=(1-\alpha) \mathrm{Q}_{1} \\
\mathrm{Q}_{4}=\alpha \mathrm{Q}_{1}\end{array}$ \\
\hline B1c & $\mathrm{MF}=f_{1}+f_{2} \sin (0.551 \pi+2 \pi \mathrm{d} / 366)$ & E1 & $\begin{array}{l}Q_{j, l a g}=Q_{2} \\
\text { with } j \in\{3,4\}\end{array}$ \\
\hline $\mathrm{C} 1$ & $\mathrm{AE}=\min \left(\right.$ Melt + Rain, $\left.K_{\mathrm{C}} \mathrm{PE}\right)$ & E2 & $\begin{array}{l}\mathrm{Q}_{\mathrm{j}, \operatorname{lag}}(t)=\sum_{\mathrm{i}=1}^{N_{b}} \omega(i) \mathrm{Q}_{\mathrm{j}}(t-i+1) \\
\text { with } \omega(\mathrm{i})=\int_{\mathrm{i}-1}^{i} 2 \mathrm{udu} / N_{b}^{2}\end{array}$ \\
\hline $\mathrm{C} 2, \mathrm{C} 3$ & $\mathrm{AE}=\operatorname{PEmin}\left(1, \mathrm{~S}_{1} / S_{\mathrm{m}}\right)$ & F1a, F2a, F3a & $\begin{array}{l}\mathrm{Q}_{5}=K_{2} S_{2}^{1+\delta} \\
\mathrm{Q}_{6}=K_{3} \mathrm{~S}_{3}\end{array}$ \\
\hline $\mathrm{C} 1$ & $\mathrm{Q}_{1}=$ Melt + Rain & $\begin{array}{l}\text { F1b, } \\
\text { F2b, F3b }\end{array}$ & $\begin{array}{l}\mathrm{Q}_{5}=K_{4} \mathrm{~S}_{2}+K_{2}\left(\overline{\mathrm{S}_{2}}-\log \left[1+\exp \left(-\overline{\mathrm{S}_{2}}\right)\right]\right) \\
\mathrm{Q}_{6}=K_{3} \mathrm{~S}_{3} \\
\text { with } \overline{\mathrm{S}_{2}}=\left(\mathrm{S}_{2}-S_{\mathrm{C}}\right) / \mathrm{m}_{\mathrm{C}} \text { and } \mathrm{m}_{\mathrm{C}}=0.1 \mathrm{~mm}^{-1}\end{array}$ \\
\hline $\mathrm{C} 2$ & $\mathrm{Q}_{1}=($ Melt + Rain $)\left(\mathrm{S}_{1} / S_{\mathrm{m}}\right)^{\beta}$ & F3a, F3b & $\mathrm{Q}_{6}=D \mathrm{~S}_{2}$ \\
\hline
\end{tabular}

ing rainfall or snowmelt events, and option $\mathrm{C} 3$, in which a leakage from the moisture-accounting store remains possible even after rainfall or snowmelt has ceased. Examples of these two moisture-accounting options can be found in the Hydrologiska Byråns Vattenbalansavdelning (HBV) (e.g. Seibert and Vis, 2012) and probability-distributed model (PDM) (Moore, 2007) rainfall-runoff models. Alternative distribution functions are available in the literature, for instance in the GR4j (Perrin et al., 2003) and FLEX (Fenicia et al., 2008b) models, but the rationale behind their use remains the same. Actual evapotranspiration is computed from the estimated PE using either a constant coefficient (option C1) or a function of the catchment moisture status (options $\mathrm{C} 2$ and C3).

\subsubsection{Runoff transformation and routing (decisions D to F)}

Runoff transformation components account for all the retention and translation processes occurring as water moves through the catchment. In practice, junction elements (decision D) and lag functions (decision E) are typically combined with one or more conceptual stores (decision F) to represent the effects of different flow pathways on the runoff process (both timing and volume). Additional elements in the form of lag functions or conceptual stores can also be used to reflect water routing in the channel network. However, in this study channel routing elements were considered useless at a daily time step. All the modelling options available for decision $\mathrm{F}$ consist of two stores. These can be arranged in parallel (options F1a and F1b), in series (options F2a and F2b), or in a combination of both (options F3a and F3b). In each case, one of the stores has a nonlinear behaviour while the other reacts linearly. Two types of nonlinear response are provided: one that relies on smoothed thresholds and different storage coefficients (options F1b, F2b and F3b), and the other that relies on power laws (options F1a, F2a and F3a). Options F1a and $\mathrm{F} 1 \mathrm{~b}$ are based on the classical parallel transfer function used in many conceptual models, such as the PDM (Moore, 2007) and the IHACRES (identification of unit hydrographs and component flows from rainfall, evapotranspiration and streamflow) (Jakeman et al., 1993) models, where one store stands for a relatively quick catchment response and the other for a slower response. The structure of options F3a and F3b is very close to the response routine of the HBV model (e.g. Seibert and Vis, 2012). Note that some combinations of modelling options were deemed unacceptable and thus not considered (e.g. D3-E1-F1a or D3-E1-F1b).

\subsection{Multi-objective optimization}

\subsubsection{Principle}

In optimization problems with at least two conflicting objectives, a set of solutions rather than a unique one exists because of the trade-offs between these objectives. A Pareto- 


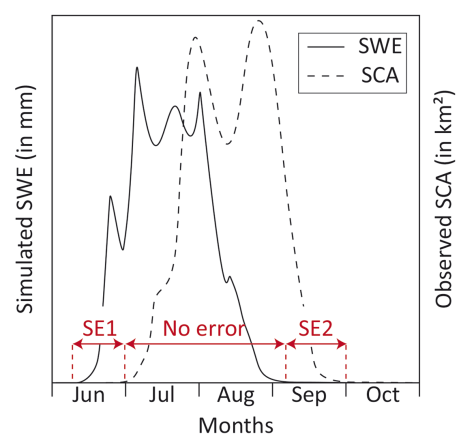

Definition of the snow error (\%): Crit4 $=\mathrm{SE}=\frac{1}{\mathrm{~N}_{\mathrm{SCA}}}(\mathrm{SE} 1+\mathrm{SE} 2)$

with $\mathrm{N}_{\mathrm{SCA}}$ the number of days with available SCA observations

Confusion matrix (days) of the SE:

\begin{tabular}{|c|c|c|c|}
\hline & \multicolumn{2}{|c|}{ SWE } \\
\hline & & $>0$ & $=0$ \\
\hline \multirow{2}{*}{ SCA } & $>0$ & No error & SE2 \\
\hline & $=0$ & SE1 & No error \\
\hline
\end{tabular}

Figure 4. Description of the snow error criterion. The overall snow error (SE) can be described as a sum of two terms, SE1 and SE2, whose values are given by a confusion matrix. In this example, water storage in the snow-accounting store (solid line) starts (SE1) and ends (SE2) sooner than what would be expected from the snowcovered area (SCA) data (dashed line).

optimal solution is achieved when it cannot be improved upon without degrading at least one of its objective criteria. The set of Pareto-optimal solutions for a given model is often called the "Pareto set" and the set of criteria corresponding to this Pareto set is usually referred to as the "Pareto front".

\subsubsection{The NSGA-II algorithm}

The Non-dominated Sorted Genetic Algorithm II (NSGAII) (Deb, 2002) was selected to calibrate the models implemented within the multiple-hypothesis framework. This algorithm has been used successfully in a number of recent hydrological studies (see, e.g., Khu and Madsen, 2005; Bekele and Nicklow, 2007; De Vos and Rientjes, 2007; Fenicia et al., 2008a; Shafii and De Smedt, 2009) and has the advantage of not needing any additional parameter (other than those common to all genetic algorithms, i.e. the initial population and the number of generations). Its most distinctive features are the use of a binary tournament selection, a simulated binary crossover and a polynomial mutation operator. For the sake of brevity, the detailed instructions of the algorithm and the conditions of its application to rainfall-runoff modelling cannot be discussed further here. Instead, the reader is referred to the aforementioned literature.

\subsubsection{Simulation periods and assessment criteria}

The simulation period was divided into a rather dry calibration period (1997-2011) and a relatively humid validation period (1982-1996). These two periods were chosen based on data availability to represent contrasted climate conditions: the two periods are separated by a shift in the IPO index, as explained in Sect. 2.3.1.

Four criteria were chosen to evaluate the models built within the multiple-hypothesis framework. The first three of them are common to both calibration and validation periods while the fourth criterion differs between the two.
The first criterion is related to the estimation of high flows and draws upon the Nash-Sutcliffe efficiency (NSE) metric:

$$
\begin{aligned}
& \text { Crit1 }=1-\mathrm{NSE}=\sum_{\mathrm{d}=1}^{\mathrm{N}}\left(\mathrm{Q}_{\mathrm{obs}}^{\mathrm{d}}-\mathrm{Q}_{\text {sim }}^{\mathrm{d}}\right)^{2} / \\
& \sum_{\mathrm{d}=1}^{\mathrm{N}}\left(\mathrm{Q}_{\mathrm{obs}}^{\mathrm{d}}-\overline{\mathrm{Q}_{\mathrm{obs}}}\right)^{2}
\end{aligned}
$$

where $\mathrm{Q}_{\mathrm{obs}}^{\mathrm{d}}$ and $\mathrm{Q}_{\text {sim }}^{\mathrm{d}}$ are the observed and simulated discharges for day $\mathrm{d}$, and $\mathrm{N}$ is the number of days with available observations.

The second criterion $\left(\mathrm{NSE}_{\log }\right)$ is related to the estimation of low flows and draws upon a modified, log version of the first criterion:

$$
\begin{aligned}
& \text { Crit2 }=1-\mathrm{NSE}_{\log }=\sum_{\mathrm{d}=1}^{\mathrm{N}}\left(\log \left(\mathrm{Q}_{\text {obs }}^{\mathrm{d}}\right)-\log \left(\mathrm{Q}_{\text {sim }}^{\mathrm{d}}\right)\right)^{2} / \\
& \sum_{\mathrm{d}=1}^{\mathrm{N}}\left(\log \left(\mathrm{Q}_{\text {obs }}^{\mathrm{d}}\right)-\log \left(\overline{\mathrm{Q}_{\text {obs }}}\right)\right)^{2}
\end{aligned}
$$

The third criterion quantifies the mean annual volume error $\left(\mathrm{VE}_{\mathrm{M}}\right)$ made in the estimation of the water balance of the catchment:

Crit3 $=\mathrm{VE}_{\mathrm{M}}=\sum_{\mathrm{y}=1}^{\mathrm{N}_{\text {years }}}\left(\left|\mathrm{V}_{\mathrm{obs}}^{\mathrm{y}}-\mathrm{V}_{\text {sim }}^{\mathrm{y}}\right| / \mathrm{V}_{\text {obs }}^{\mathrm{y}}\right) / \mathrm{N}_{\text {years }}$

where $\mathrm{V}_{\text {obs }}^{\mathrm{y}}$ and $\mathrm{V}_{\text {sim }}^{\mathrm{y}}$ are the observed and simulated volumes for year $\mathrm{y}$, and $\mathrm{N}_{\text {years }}$ is the number of years of the simulation period.

The fourth criterion (Crit4) differs between the two simulation periods. In calibration, snow-covered areas (SCA) estimated from the MODIS data were used to evaluate the consistency of snow-accounting modelling options in terms of snow presence or absence at the catchment scale. The objective was to quantify the error made in simulating the seasonal dynamics of snow accumulation, storage and melt processes. Following Parajka and Blöschl (2008), the snow error (SE) was defined as the total number of days when the snowaccounting store of options B1a, B1b and B1c disagreed with the MODIS data as to whether snow was present in the basin (Fig. 4). The number of days with simulation errors is eventually divided by the total number of days with available MODIS data to express SE as a percentage.

In validation, a cumulated volume error was used to replace the snow error criterion that could not be computed due to a lack of remotely sensed data over this period:

$$
\text { Crit4 }=\mathrm{VE}_{\mathrm{C}}=\left|\sum_{\mathrm{y}=1}^{\mathrm{N}_{\text {years }}} \mathrm{V}_{\mathrm{obs}}^{\mathrm{y}}-\sum_{\mathrm{y}=1}^{N_{\text {years }}} \mathrm{V}_{\text {sim }}^{\mathrm{y}}\right| / \sum_{\mathrm{y}=1}^{\mathrm{N}_{\text {years }}} \mathrm{V}_{\mathrm{obs}}^{\mathrm{y}}
$$




\subsection{Model selection, model analysis and ensemble modelling}

Finally, a total of 72 model structures were implemented and tested within the multi-objective and multiple-hypothesis frameworks. In addition to their names and for purposes of simplicity, these 72 model hypotheses are given a number from 1 to 72 corresponding to their order of appearance in the simulation process (see, e.g., Sect. 4.1).

Model hypotheses can be thought of as points $x$ in the space of performance measures. One possible way to locate these points in space is to consider that each coordinate $\left(x_{i}\right)_{i=1 \ldots 4}$ of $x$ is given by the best performance obtained along the Pareto front of model $x$ with respect to the $i$ th criterion described in Sect. 3.3.2. A clustering technique based on the fuzzy c-means algorithm (Bezdek et al., 1983) and the initialization procedure developed by Chiu (1994) was chosen to explore this multi-objective space and identify natural groupings among model hypotheses. To facilitate comparison between calibration and validation, the clustering operations were repeated independently for each period. The whole experiment, from model-building to multi-objective optimization and cluster identification, was repeated several times to ensure that the final composition of the clusters remains the same.

Once the composition of each cluster was established, it was possible to identify a set of "best-performing" clusters for each simulation period, i.e. a set of clusters with the smallest Euclidian distances to the origin of the objective space. The model structures of these "best-performing" clusters can be regarded as an equally acceptable representations of the system. An important indicator of structural uncertainty is the extent to which the simulation bounds derived from the Pareto sets of these models reproduce the various features of the observed hydrograph. The overall uncertainty envelope should be wide enough to include a large proportion of the observed discharge but not so wide that its representation of the various aspects of the hydrograph (rising limb, peak discharge, falling limb, baseflow) becomes meaningless. In this study, priority was given to maintaining at its lowest value the number of outlying observations before searching for the best combination of models which minimized the envelope area. This was achieved iteratively through the following steps:

1. Start with an initial ensemble composed of the $N_{\max }$ models identified as members of the best-performing clusters in both calibration and validation (i.e. models which fail the validation test are ruled out).

2. From now on, consider only the calibration period. Add up the $N_{\max }$ individual simulation envelopes that can be obtained from the Pareto sets of the $N_{\max }$ models (hereafter referred to as the "Pareto-envelopes").
3. Estimate the maximum number of observations enclosed within the resulting overall envelope, $N_{\text {obs }}\left(N_{\max }\right)$, and calculate the area of this envelope, $\operatorname{Area}\left(N_{\max }\right)$.

4. For $k=1$ to $N_{\max }$ :

(a) Identify the $\left(\begin{array}{c}N_{\max } \\ N_{\max }-k\end{array}\right)$ possible combinations of $N_{\text {max }}$ models taken $N_{\max }-k$ at a time.

(b) For each of these combinations,

- add up the individual Pareto-envelopes of the $N_{\max }-k$ models and calculate the number of observations enclosed within the bounds of the resulting overall envelope, $N_{\mathrm{obs}}\left(N_{\max }-k\right)$;

- if $N_{\mathrm{obs}}\left(N_{\mathrm{max}}-k\right)=N_{\mathrm{obs}}\left(N_{\max }\right)$;

- if $\operatorname{Area}\left(N_{\max }-k\right)<\operatorname{Area}\left(N_{\max }-k+1\right) \quad-$ accept the current combination;

- if $N_{\text {obs }}\left(N_{\max }-k\right)<N_{\text {obs }}\left(N_{\max }\right)-$ reject the current combination.

(c) If all the possible combinations of $N_{\max }-k$ models are rejected, break the loop. The final ensemble of models to consider is the last accepted combination of $N_{\max }-k+1$ models.

\section{Results}

\subsection{Model hypotheses evaluation}

\subsubsection{Cluster analysis}

The 72 model hypotheses can be grouped into five clusters in calibration and six in validation. Table 3 displays the coordinates of the cluster centroids and gives, for each cluster, the number of points with membership values above $50 \%$. Figure 5 shows the projections of these clusters onto three possible two-dimensional (2-D) subspaces of the objective space (the three other subspaces being omitted for the sake of brevity). Each cluster is given a rank (from 1 to 5 or 6 ) reflecting its distance from the origin of the coordinate system. As is evident from both Fig. 5 and Table 3, most of the bestperforming structures can be found in cluster 1 . This is particularly clear in the planes defined by the high-flow (Crit1) and low-flow (Crit2) criteria (Fig. 5), where all clusters tend to line up along a diagonal axis (dashed line). In contrast, a small trade-off between cluster 1 and cluster 2 can be observed in calibration in the plane defined by the high-flow (Crit1) and volume error (Crit3) criteria: models from cluster 2 (respectively cluster 1 ) tend to perform slightly better than those from cluster 1 (respectively cluster 2) with respect to Crit3 (respectively Crit1). However, this trade-off disappears in validation. Similar comments can be made about the other 2-D subspaces (not shown here). In the following analysis, 
(a) Calibration period (1997-2011)
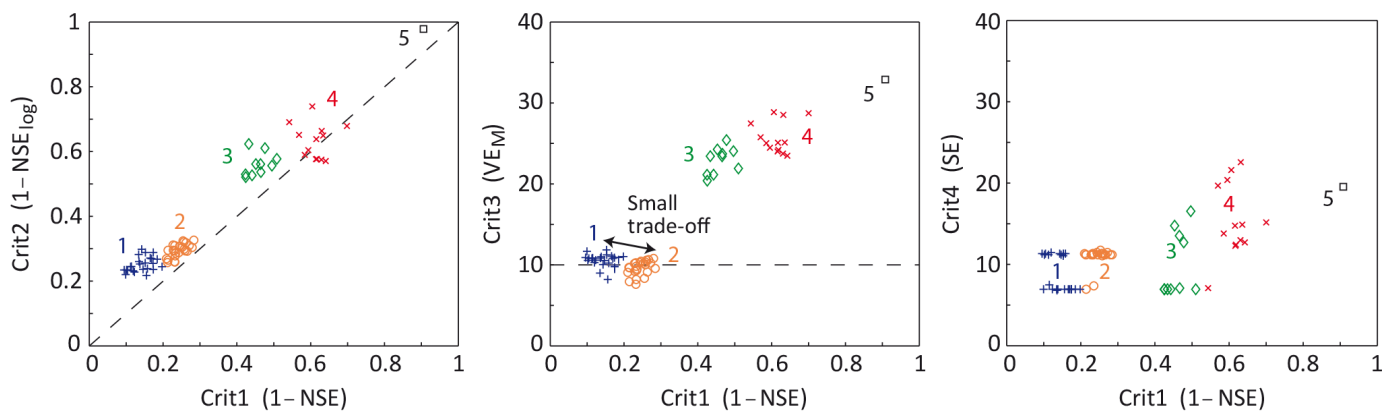

(b) Validation period (1982-1996)
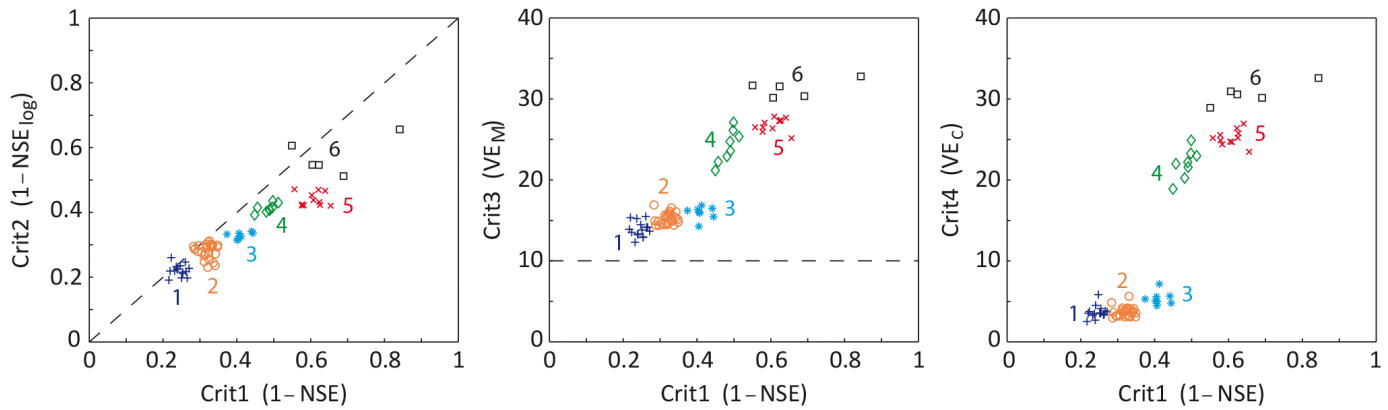

Figure 5. Projections of the clusters onto three possible planes of the objective space in calibration and validation. As explained in Sect. 3.3, each point represents a different model hypothesis.

cluster 1 will be considered as the only best-performing cluster. This cluster encompasses 24 members in calibration as against 15 in validation, indicating that several model structures do not pass the validation test (namely model nos. 30, 32, 49, 52, 53, 55, 66, 67, 69 and 72, as shown in Table 4).

Several observations can be made regarding the composition of cluster 1 in both simulation periods. As can be seen from the values listed in Table 4, it is not possible to pick out a single, unambiguous model hypothesis that would perform better than the others with respect to all criteria. On the one hand, there appears to be several equally acceptable structures for each individual criterion. Model nos. 22 (A1B1a-C3-D2-E1-F2b), 46 (A1-B1b-C3-D2-E1-F2b) and 54 (A1-B1c-C1-D3-E2-F1b), for instance, yield very similar values of the high-flow criterion (Crit1), despite some differences in their modelling options. This illustrates the equifinality of model structures in reproducing one aspect of the system behaviour. On the other hand, some structures seem more appropriate for the simulation of high flows or snow dynamics while others appear to be better at reproducing low flows or estimating the annual water balance of the catchment. This indicates trade-offs between model structures in reproducing several aspects of the system behaviour. It is however possible to identify some recurring patterns among the modelling options present in (or absent from) cluster 1 in both periods. First, option B1c is the most represented snowmelt-accounting hypothesis, despite an increase in the number of alternative options (B1a, B1b) in validation. More strikingly, option $\mathrm{C} 2$ is totally absent from cluster 1 in both periods. Single-flux combinations (C1-D1 and C3-D2) and their splitting counterparts (C1-D3 and C3-D1) tend to be equally well represented, thus providing evidence of significant equifinality among these conceptual representations. Finally, runoff transformation options based on a threshold-like behaviour (F1b, F2b and F3b) account for $75 \%$ of model hypotheses in calibration and over $90 \%$ in validation. In particular, option F3a turns out to be completely absent from cluster 1 in both periods while models based on option F2a (nos. 49, 55, 67 and 69) fail the validation test. On the opposite, option F2b is particularly well represented.

\subsubsection{Pareto analysis}

In general, valuable insight can be gained from the mapping of Pareto fronts in the space of performance measures. While a full description of all the Pareto fronts obtained in calibration is not possible here due to space limitations, two model hypotheses are used to illustrate this point. Figure 6 shows the Pareto-optimal solutions of model nos. 49 (A1-B1c-C1D1-E1-F2a) and 50 (A1-B1c-C1-D1-E1-F2b) plotted in two dimensions for different combinations of two of the four objective functions used in calibration. Note that these two models differ only in their runoff transformation options (F2a vs. F2b) so that the comparison can be made in a controlled way. Trade-offs between the high-flow (Crit1) and low-flow (Crit2) criteria are clearly more important with option F2a 
(a) Model hypothesis no. 49 (A1-B1c-C1-D1-E1-F2a-G1)
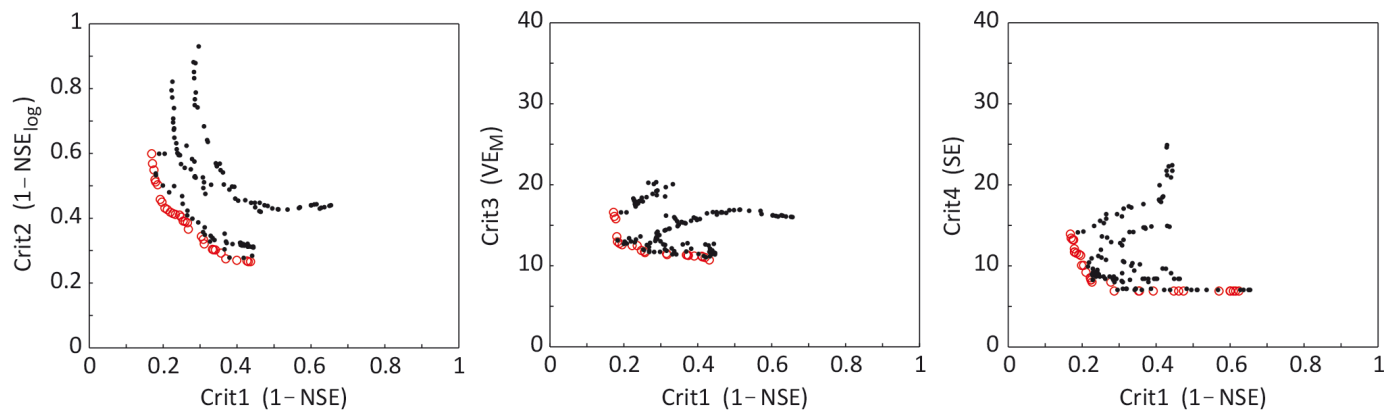

(b) Model hypothesis no. 50 (A1-B1c-C1-D1-E1-F2b-G1)
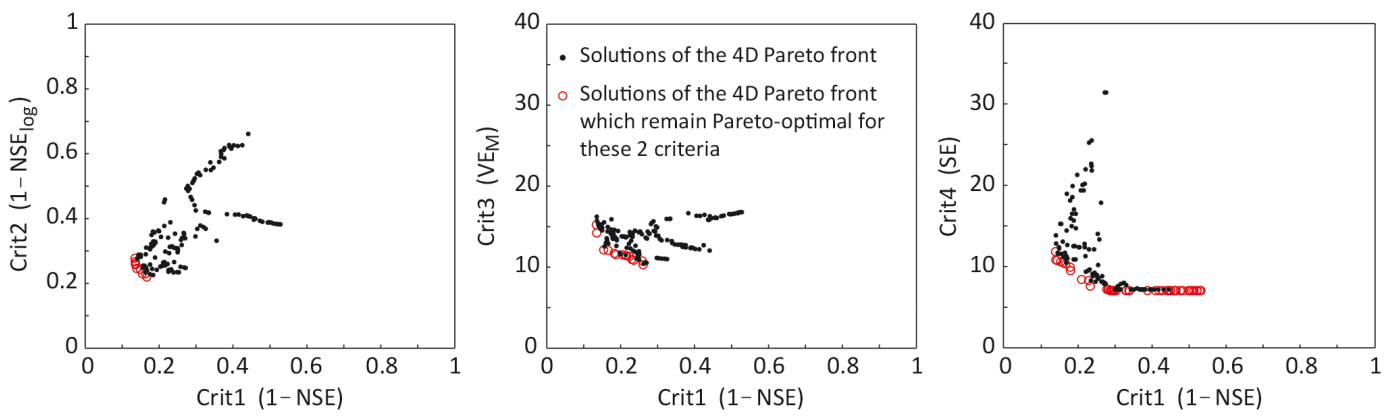

Figure 6. Projections of the Pareto fronts of model hypotheses (a) no. 49 (A1-B1c-C1-D1-E1-F2a) and (b) no. 50 (A1-B1c-C1-D1-E1-F2b) onto three possible two-dimensional subspaces of the objective space.

(a) Competing snow options: B1a vs B1b (+ C3-D2-E1)

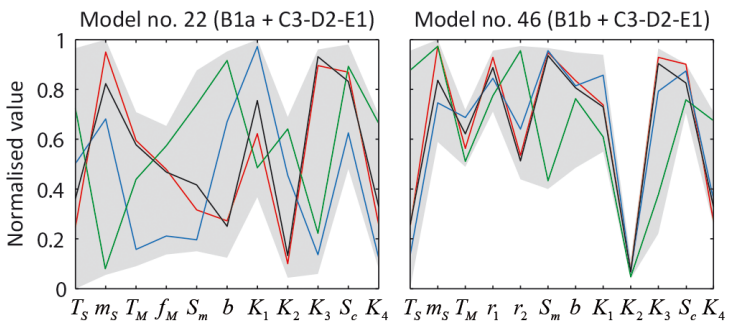

(c) Competing runoff transformation options: F2a vs F2b

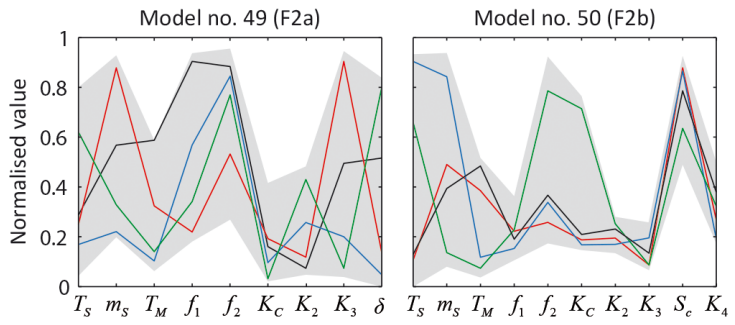

(b) Competing snow options: B1a vs B1b (+C3-D1-E2)

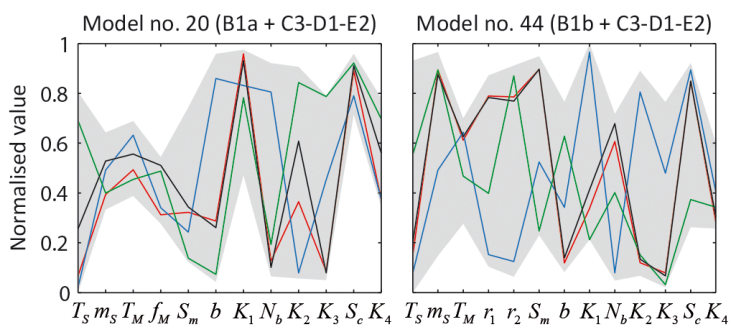

(d) Competing runoff transformation options: Fla vs F1b

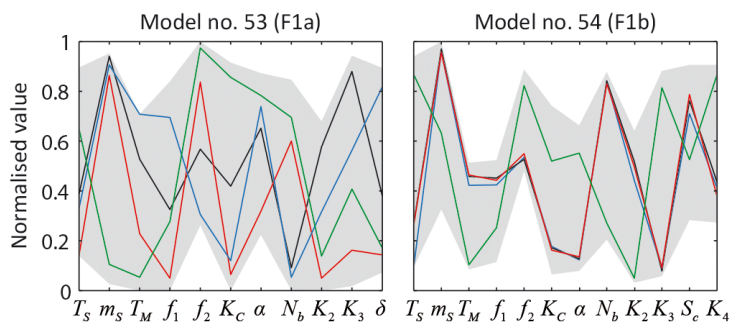

Figure 7. Estimated normalized ranges of the Pareto-optimal sets of eight alternative model structures differing in at least one of their components. The coloured lines stand for the best solutions obtained in calibration with respect to the high-flow criterion (in black), the low-flow criterion (in red), the mean annual volume error (in blue) and the snow error (in green).

(Fig. 6a) than with option F2b (Fig. 6b). This means that option F2a is less efficient in reproducing simultaneously high and low flows and explains why this option disappears from cluster 1 in validation. By contrast, the other pairs of criteria
(Crit1-Crit3, Crit1-Crit4) displayed in Fig. 6 appear to be less useful in differentiating between the two models. 
Table 2. Parameters used in the various modelling options with their signification and initial sampling.

\begin{tabular}{|c|c|c|c|c|}
\hline Parameter & Options & Signification & Units & Initial range \\
\hline$T_{\mathrm{S}}$ & A1 & $\begin{array}{l}\text { Rain/snow partitioning temperature } \\
\text { threshold }\end{array}$ & ${ }^{\circ} \mathrm{C}$ & -10 to 10 \\
\hline$m_{\mathrm{S}}$ & A1 & $\begin{array}{l}\text { Rain/snow partitioning smoothing } \\
\text { parameter }\end{array}$ & - & $0.01-3$ \\
\hline$T_{\mathrm{M}}$ & $\mathrm{B} 1 \mathrm{a}, \mathrm{B} 1 \mathrm{~b}, \mathrm{~B} 1 \mathrm{c}$ & Snowmelt temperature threshold & ${ }^{\circ} \mathrm{C}$ & -10 to 10 \\
\hline$f_{\mathrm{M}}$ & B1a & Constant melt factor & ${ }^{\circ} \mathrm{Cmm}^{-1}$ & $0-10$ \\
\hline$r_{1}$ & $\mathrm{~B} 1 \mathrm{~b}$ & $\begin{array}{l}\text { Coefficient for computation of the } \\
\text { variable melt factor }\end{array}$ & ${ }^{\circ} \mathrm{Cmm}^{-1}$ & $1-5$ \\
\hline$r_{2}$ & B1b & $\begin{array}{l}\text { Coefficient for computation of the } \\
\text { variable melt factor }\end{array}$ & ${ }^{\circ} \mathrm{Cmm}^{-1}$ & $1-5$ \\
\hline$f_{1}$ & $\mathrm{~B} 1 \mathrm{c}$ & $\begin{array}{l}\text { Coefficient for computation of the } \\
\text { variable melt factor }\end{array}$ & ${ }^{\circ} \mathrm{Cmm}^{-1}$ & $1-5$ \\
\hline$f_{2}$ & $\mathrm{~B} 1 \mathrm{c}$ & $\begin{array}{l}\text { Coefficient for computation of the } \\
\text { variable melt factor }\end{array}$ & ${ }^{\circ} \mathrm{Cmm}^{-1}$ & $1-5$ \\
\hline$K_{\mathrm{C}}$ & $\mathrm{C} 1$ & Evapotranspiration coefficient & - & $0.05-0.5$ \\
\hline$S_{\mathrm{m}}$ & $\mathrm{C} 2, \mathrm{C} 3$ & $\begin{array}{l}\text { Maximum storage capacity of the } \\
\text { moisture-accounting store }\end{array}$ & $\mathrm{mm}$ & $10-100$ \\
\hline$\beta$ & $\mathrm{C} 2$ & Shape parameter & - & $0.1-3$ \\
\hline$b$ & $\mathrm{C} 3$ & Shape parameter of Pareto distribution & - & $0.1-3$ \\
\hline$K_{1}$ & $\mathrm{C} 3$ & Infiltration coefficient & $d^{-1}$ & $0.001-0.7$ \\
\hline$\alpha$ & D3 & Splitting parameter & - & $0.1-0.9$ \\
\hline$N_{b}$ & E2 & Number of time steps in the lag routine & - & $1-6$ \\
\hline$K_{2}$ & F1a to F3b & Storage coefficient & $d^{-1}$ & $0.01-0.99$ \\
\hline$K_{3}$ & F1a to F3b & Storage coefficient & $d^{-1}$ & $\begin{array}{c}0.001-0.01(\mathrm{~F} 1 \mathrm{a}, \mathrm{F} 1 \mathrm{~b}, \mathrm{~F} 3 \mathrm{a}, \mathrm{F} 3 \mathrm{~b}) \\
0.001-0.01(\mathrm{~F} 2 \mathrm{a}, \mathrm{F} 2 \mathrm{~b})\end{array}$ \\
\hline$\delta$ & F1a, F2a, F3a & $\begin{array}{l}\text { Power law parameter of the non-linear } \\
\text { store in the runoff transformation module }\end{array}$ & - & $0-1$ \\
\hline$S_{\mathrm{c}}$ & $\mathrm{F} 1 \mathrm{~b}, \mathrm{~F} 2 \mathrm{~b}, \mathrm{~F} 3 \mathrm{~b}$ & $\begin{array}{l}\text { Threshold parameter of the non-linear } \\
\text { store in the runoff transformation module }\end{array}$ & $\mathrm{mm}$ & $10-300$ \\
\hline$D$ & F3a, F3b & Recharge coefficient & $d^{-1}$ & $0.001-0.5$ \\
\hline$K_{4}$ & $\mathrm{~F} 1 \mathrm{~b}, \mathrm{~F} 2 \mathrm{~b}, \mathrm{~F} 3 \mathrm{~b}$ & Storage coefficient & $d^{-1}$ & $0.001-0.01$ \\
\hline
\end{tabular}

Table 3. Coordinates of the cluster centroids in the four-dimensional (4-D) space of performance measures. The number of models with membership values $>50 \%\left(N_{50 \%}\right)$ is given for each cluster.

\begin{tabular}{|c|c|c|c|c|c|}
\hline \multicolumn{6}{|c|}{ Calibration period (1997-2011) } \\
\hline Cluster no. & Crit1 (1-NSE) & Crit2 (1-NSE $\left.{ }_{\log }\right)$ & Crit3 $\left(\mathrm{VE}_{\mathrm{M}}\right)(\%)$ & Crit4 (SE) (\%) & $N_{50 \%}$ \\
\hline 1 & 0.15 & 0.25 & 10 & 9 & 24 \\
\hline 2 & 0.23 & 0.30 & 10 & 10 & 24 \\
\hline 3 & 0.49 & 0.58 & 23 & 11 & 10 \\
\hline 4 & 0.60 & 0.62 & 25 & 16 & 13 \\
\hline 5 & 0.92 & 0.97 & 33 & 20 & 1 \\
\hline \multicolumn{6}{|c|}{ Validation period (1982-1996) } \\
\hline Cluster no. & Crit1 (1-NSE) & Crit2 $\left(1-\mathrm{NSE}_{\log }\right)$ & Crit3 $\left(\mathrm{VE}_{\mathrm{M}}\right)(\%)$ & Crit4 $\left(\mathrm{VE}_{\mathrm{C}}\right)(\%)$ & $N_{50 \%}$ \\
\hline 1 & 0.24 & 0.21 & 14 & 3 & 15 \\
\hline 2 & 0.32 & 0.29 & 15 & 4 & 25 \\
\hline 3 & 0.38 & 0.31 & 15 & 5 & 8 \\
\hline 4 & 0.51 & 0.42 & 25 & 23 & 8 \\
\hline 5 & 0.61 & 0.44 & 27 & 27 & 11 \\
\hline 6 & 0.61 & 0.51 & 30 & 33 & 5 \\
\hline
\end{tabular}


Table 4. Detailed composition of cluster 1 in calibration and validation. The tables indicate the numbers and the names of the models as well as their number of parameters NP. For each criterion only the best performance value obtained along the Pareto front is given. $N_{\text {par }}(\%)$ represents the proportion of observations enclosed within the simulation bounds of each Pareto set of solutions. Asterisks are used to indicate the models which are not in the best-performing group (cluster 1) either in calibration or in validation.

\begin{tabular}{|c|c|c|c|c|c|c|c|}
\hline \multicolumn{8}{|c|}{ Calibration period (1997-2011) } \\
\hline Model no. & Model name (options) & NP & NSE & $\mathrm{NSE}_{\log }$ & $\mathrm{VE}_{\mathrm{M}}(\%)$ & SE $(\%)$ & $N_{\text {par }}(\%)$ \\
\hline 2 & $\mathrm{~A} 1-\mathrm{B} 1 \mathrm{a}-\mathrm{C} 1-\mathrm{D} 1-\mathrm{E} 1-\mathrm{F} 2 \mathrm{~b}$ & 9 & 0.87 & 0.76 & 10.6 & 11.2 & 76.0 \\
\hline 4 & A1-B1a-C1-D1-E1-F3b & 10 & 0.84 & 0.77 & 10.4 & 11.2 & 53.2 \\
\hline 8 & A1-B1a-C1-D3-E2-F2b & 11 & 0.83 & 0.75 & 11.7 & 11.1 & 76.5 \\
\hline 20 & A1-B1a-C3-D1-E2-F2b & 12 & 0.83 & 0.76 & 10.0 & 11.4 & 60.0 \\
\hline 22 & A1-B1a-C3-D2-E1-F2b & 11 & 0.90 & 0.77 & 10.4 & 11.2 & 64.1 \\
\hline 26 & $\mathrm{~A} 1-\mathrm{B} 1 \mathrm{~b}-\mathrm{C} 1-\mathrm{D} 1-\mathrm{E} 1-\mathrm{F} 2 \mathrm{~b}$ & 10 & 0.87 & 0.77 & 10.1 & 11.5 & 58.4 \\
\hline $30(*)$ & A1-B1b-C1-D3-E2-F1b & 12 & 0.84 & 0.70 & 9.8 & 11.4 & 69.6 \\
\hline $32(*)$ & $\mathrm{A} 1-\mathrm{B} 1 \mathrm{~b}-\mathrm{C} 1-\mathrm{D} 3-\mathrm{E} 2-\mathrm{F} 2 \mathrm{~b}$ & 12 & 0.83 & 0.71 & 11.1 & 11.4 & 68.4 \\
\hline 44 & $\mathrm{~A} 1-\mathrm{B} 1 \mathrm{~b}-\mathrm{C} 3-\mathrm{D} 1-\mathrm{E} 2-\mathrm{F} 2 \mathrm{~b}$ & 13 & 0.89 & 0.77 & 10.6 & 11.4 & 63.4 \\
\hline 46 & $\mathrm{~A} 1-\mathrm{B} 1 \mathrm{~b}-\mathrm{C} 3-\mathrm{D} 2-\mathrm{E} 1-\mathrm{F} 2 \mathrm{~b}$ & 12 & 0.90 & 0.76 & 10.7 & 11.4 & 45.4 \\
\hline $49(*)$ & $\mathrm{A} 1-\mathrm{B} 1 \mathrm{c}-\mathrm{C} 1-\mathrm{D} 1-\mathrm{E} 1-\mathrm{F} 2 \mathrm{a}$ & 9 & 0.82 & 0.73 & 10.9 & 7.0 & 67.0 \\
\hline 50 & $\mathrm{~A} 1-\mathrm{B} 1 \mathrm{c}-\mathrm{C} 1-\mathrm{D} 1-\mathrm{E} 1-\mathrm{F} 2 \mathrm{~b}$ & 10 & 0.86 & 0.77 & 10.4 & 7.0 & 67.4 \\
\hline $52(*)$ & $\mathrm{A} 1-\mathrm{B} 1 \mathrm{c}-\mathrm{C} 1-\mathrm{D} 1-\mathrm{E} 1-\mathrm{F} 3 \mathrm{~b}$ & 11 & 0.85 & 0.72 & 8.8 & 8.1 & 65.7 \\
\hline $53(*)$ & A1-B1c-C1-D3-E2-F1a & 11 & 0.79 & 0.76 & 10.8 & 7.0 & 63.8 \\
\hline 54 & $\mathrm{~A} 1-\mathrm{B} 1 \mathrm{c}-\mathrm{C} 1-\mathrm{D} 3-\mathrm{E} 2-\mathrm{F} 1 \mathrm{~b}$ & 12 & 0.90 & 0.78 & 11.5 & 7.5 & 55.7 \\
\hline $55(*)$ & $\mathrm{A} 1-\mathrm{B} 1 \mathrm{c}-\mathrm{C} 1-\mathrm{D} 3-\mathrm{E} 2-\mathrm{F} 2 \mathrm{a}$ & 11 & 0.80 & 0.73 & 10.7 & 7.0 & 54.5 \\
\hline 56 & $\mathrm{~A} 1-\mathrm{B} 1 \mathrm{c}-\mathrm{C} 1-\mathrm{D} 3-\mathrm{E} 2-\mathrm{F} 2 \mathrm{~b}$ & 12 & 0.85 & 0.75 & 10.8 & 7.6 & 76.3 \\
\hline 65 & A1-B1c-C3-D1-E2-F1a & 12 & 0.83 & 0.78 & 8.0 & 7.7 & 65.0 \\
\hline $66(*)$ & $\mathrm{A} 1-\mathrm{B} 1 \mathrm{c}-\mathrm{C} 3-\mathrm{D} 1-\mathrm{E} 2-\mathrm{F} 1 \mathrm{~b}$ & 13 & 0.81 & 0.77 & 9.6 & 6.8 & 63.5 \\
\hline $67(*)$ & $\mathrm{A} 1-\mathrm{B} 1 \mathrm{c}-\mathrm{C} 3-\mathrm{D} 1-\mathrm{E} 2-\mathrm{F} 2 \mathrm{a}$ & 12 & 0.81 & 0.75 & 10.7 & 7.0 & 73.7 \\
\hline 68 & $\mathrm{~A} 1-\mathrm{B} 1 \mathrm{c}-\mathrm{C} 3-\mathrm{D} 1-\mathrm{E} 2-\mathrm{F} 2 \mathrm{~b}$ & 13 & 0.85 & 0.74 & 10.6 & 6.8 & 74.5 \\
\hline $69(*)$ & $\mathrm{A} 1-\mathrm{B} 1 \mathrm{c}-\mathrm{C} 3-\mathrm{D} 2-\mathrm{E} 1-\mathrm{F} 2 \mathrm{a}$ & 11 & 0.82 & 0.73 & 10.6 & 7.0 & 51.8 \\
\hline 70 & $\mathrm{~A} 1-\mathrm{B} 1 \mathrm{c}-\mathrm{C} 3-\mathrm{D} 2-\mathrm{E} 1-\mathrm{F} 2 \mathrm{~b}$ & 12 & 0.87 & 0.76 & 10.7 & 7.5 & 76.4 \\
\hline $72(*)$ & $\mathrm{A} 1-\mathrm{B} 1 \mathrm{c}-\mathrm{C} 3-\mathrm{D} 2-\mathrm{E} 1-\mathrm{F} 3 \mathrm{~b}$ & 13 & 0.81 & 0.71 & 9.8 & 7.1 & 69.0 \\
\hline \multicolumn{8}{|c|}{ Validation period (1982-1996) } \\
\hline Model no. & Model name & NP & NSE & $\mathrm{NSE}_{\log }$ & $\mathrm{VE}_{\mathrm{M}}(\%)$ & $\mathrm{VE}_{\mathrm{C}}(\%)$ & $N_{\text {par }}(\%)$ \\
\hline 2 & $\mathrm{~A} 1-\mathrm{B} 1 \mathrm{a}-\mathrm{C} 1-\mathrm{D} 1-\mathrm{E} 1-\mathrm{F} 2 \mathrm{~b}$ & 9 & 0.75 & 0.78 & 13.3 & 2.7 & 87.1 \\
\hline 4 & A1-B1a-C1-D1-E1-F3b & 10 & 0.73 & 0.80 & 14.1 & 3.8 & 50.0 \\
\hline 8 & $\mathrm{~A} 1-\mathrm{B} 1 \mathrm{a}-\mathrm{C} 1-\mathrm{D} 3-\mathrm{E} 2-\mathrm{F} 2 \mathrm{~b}$ & 11 & 0.75 & 0.76 & 14.5 & 5.8 & 84.8 \\
\hline 20 & $\mathrm{~A} 1-\mathrm{B} 1 \mathrm{a}-\mathrm{C} 3-\mathrm{D} 1-\mathrm{E} 2-\mathrm{F} 2 \mathrm{~b}$ & 12 & 0.72 & 0.77 & 13.7 & 3.7 & 58.4 \\
\hline 22 & $\mathrm{~A} 1-\mathrm{B} 1 \mathrm{a}-\mathrm{C} 3-\mathrm{D} 2-\mathrm{E} 1-\mathrm{F} 2 \mathrm{~b}$ & 11 & 0.76 & 0.78 & 12.3 & 3.3 & 75.3 \\
\hline 26 & $\mathrm{~A} 1-\mathrm{B} 1 \mathrm{~b}-\mathrm{C} 1-\mathrm{D} 1-\mathrm{E} 1-\mathrm{F} 2 \mathrm{~b}$ & 10 & 0.74 & 0.78 & 12.9 & 3.5 & 70.2 \\
\hline $42(*)$ & A1-B1b-C3-D1-E2-F1b & 13 & 0.73 & 0.75 & 15.6 & 3.3 & 62.7 \\
\hline 44 & $\mathrm{~A} 1-\mathrm{B} 1 \mathrm{~b}-\mathrm{C} 3-\mathrm{D} 1-\mathrm{E} 2-\mathrm{F} 2 \mathrm{~b}$ & 13 & 0.74 & 0.79 & 13.0 & 4.1 & 69.3 \\
\hline 46 & A1-B1b-C3-D2-E1-F2b & 12 & 0.76 & 0.77 & 15.2 & 3.4 & 48.4 \\
\hline 50 & $\mathrm{~A} 1-\mathrm{B} 1 \mathrm{c}-\mathrm{C} 1-\mathrm{D} 1-\mathrm{E} 1-\mathrm{F} 2 \mathrm{~b}$ & 10 & 0.78 & 0.81 & 13.9 & 2.5 & 73.1 \\
\hline 54 & A1-B1c-C1-D3-E2-F1b & 12 & 0.77 & 0.78 & 15.3 & 3.5 & 60.8 \\
\hline 56 & $\mathrm{~A} 1-\mathrm{B} 1 \mathrm{c}-\mathrm{C} 1-\mathrm{D} 3-\mathrm{E} 2-\mathrm{F} 2 \mathrm{~b}$ & 12 & 0.75 & 0.77 & 13.2 & 4.5 & 81.3 \\
\hline 65 & A1-B1c-C3-D1-E2-F1a & 12 & 0.74 & 0.80 & 13.8 & 3.6 & 73.0 \\
\hline 68 & $\mathrm{~A} 1-\mathrm{B} 1 \mathrm{c}-\mathrm{C} 3-\mathrm{D} 1-\mathrm{E} 2-\mathrm{F} 2 \mathrm{~b}$ & 13 & 0.77 & 0.74 & 13.5 & 3.7 & 78.7 \\
\hline 70 & $\mathrm{~A} 1-\mathrm{B} 1 \mathrm{c}-\mathrm{C} 3-\mathrm{D} 2-\mathrm{E} 1-\mathrm{F} 2 \mathrm{~b}$ & 12 & 0.73 & 0.78 & 14.2 & 3.4 & 79.4 \\
\hline
\end{tabular}

Further insight into the structural strengths and weaknesses of model hypotheses can be obtained by determining how parameter values vary along the Pareto fronts of the models. A large "Pareto range" in some parameters indicates structural deficiencies in the corresponding model compo- nents (see, e.g., Gupta et al., 1998) or a lower sensitivity of model outputs to those parameters (Engeland et al., 2006). For purposes of clarity, Fig. 7 focuses on eight illustrative structures identified as members of cluster 1 in calibration. The models are paired in such a way that two models of the 


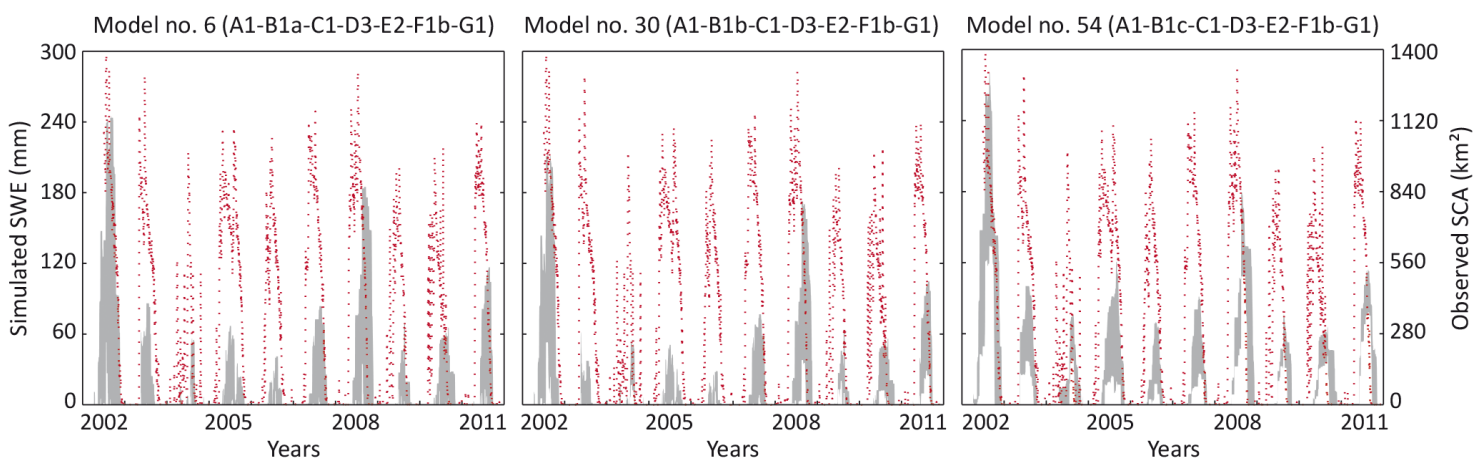

Figure 8. Comparison of MODIS-based SCA data (red dashed lines) with the snow water equivalent (SWE) simulations (shaded areas) of model nos. 6, 30 and 54. The shaded area corresponds to the range of SWE simulations obtained from the Pareto sets of these models.

same pair differ in only one modelling option. Thus, the effects of potential interactions between model constituents are more likely to be detected. Parameter values are normalized using the lower and upper limits given in Table 2 so that all of them lie between 0 and 1 . Different colours are used to indicate the parameter sets associated with the smallest high-flow (in black), low-flow (in red), volume (in blue) and snow (in green) errors. The extent to which these coloured solutions converge toward the same parameter values or diverge from each other determines the level of parameter identifiability of each model hypothesis. In terms of snow-accounting options, a distinction can be made between snow accumulation paramaters ( $T_{\mathrm{S}}$ and $\left.m_{\mathrm{S}}\right)$, whose ranges of variation appear to be large in all cases, and snowmelt parameters $\left(T_{\mathrm{M}}, f_{\mathrm{M}}, r_{1}\right.$, $r_{2}, f_{1}, f_{2}$ ), whose levels of identifiability depend on interactions with the other model components. In Fig. 7a, the Pareto range of snowmelt parameters decreases in width when moving from option B1a to B1b and using the combination of options C3-D2-E1. Yet changing this combination into C3D1-E2 has the opposite effect (Fig. 7b): parameter uncertainty now decreases when moving from option B1b to B1a. In terms of runoff transformation parameters $\left(\alpha, N_{b}, K_{2}, K_{3}\right.$, $\delta, S_{C}$ and $K_{4}$ ), the black and red solutions are closer to each other when options F2b (Fig. 7a, b and c) and F1b (Fig. 7d) are used. By contrast, options F2a (Fig. 7c) and F1a (Fig. 7d) require very different parameter sets to adequately simulate both low and high flows. Again, this suggests that runoff transformation options based on a threshold-like behaviour may be more consistent with the observed data than those based on a power law relationship. It should be noted, however, that relatively large Pareto ranges in some runoff transformation parameters (e.g. $K_{2}$ and $K_{3}$ ) may still be required to obtain small volume and snow errors at the same time as high low-flow and high-flow performances (e.g. model nos. 44 and 54). Interestingly, the black, red and blue solutions of model nos. 49, 50, 53 and 54 also converge towards the same low values of parameter $K_{C}$ (evapotranspiration coefficient) independently of runoff transformation options.
Drawing any conclusion at this stage about the links between parameter identifiability and model performance might be somewhat hazardous. Other examples (not shown here) show that a model structure may have highly identifiable parameter values in calibration and yet not be suited to the conditions prevailing in validation. Also, a reduction of parameter uncertainty as is the case with options F2b and F1b often comes with a greater number of parameters.

Finally, a better understanding of the reasons why some models, or modelling options, work better than others is provided by the simulation bounds (or Pareto-envelopes) derived from the Pareto sets of these models. Figure 8 shows the Pareto-envelopes of the snow water equivalent (SWE) internal state variable obtained with three competing model hypotheses (nos. 6, 30 and 54) differing only in their snowmeltaccounting options (respectively B1a, B1b and B1c). Note that only the last two of these models $(30,54)$ belong to cluster 1 in calibration (see Table 4). Simulated snow accumulation starts later than expected with all modelling options (B1a, B1b and B1c). As will be further discussed in Sect. 5.2, this is likely to indicate systematic errors in the input precipitation and/or MODIS-based SCA data. On the whole, the envelope widths suggest a reduction in the uncertainty associated with the prediction of snow seasonal dynamics when moving from option B1a to option B1c. This is consistent with the mean annual snow errors reported in Table 4, which are significantly lower with option B1c independently of the other model options. It must be acknowledged, however, that even this option (B1c) fails to capture the seasonal dynamics of snow accumulation and melt during several years of the period. The release of water from the snow-accounting store of model no. 54 continues well after the end of the observed snowmelt season in 2008, 2009, 2010 and 2011. On the contrary, the simulated snowmelt season tends to end sooner than expected with model no. 30 in 2003, 2004, 2005 and 2006. In that case, options B1b and B1c appear to be somewhat complementary. 

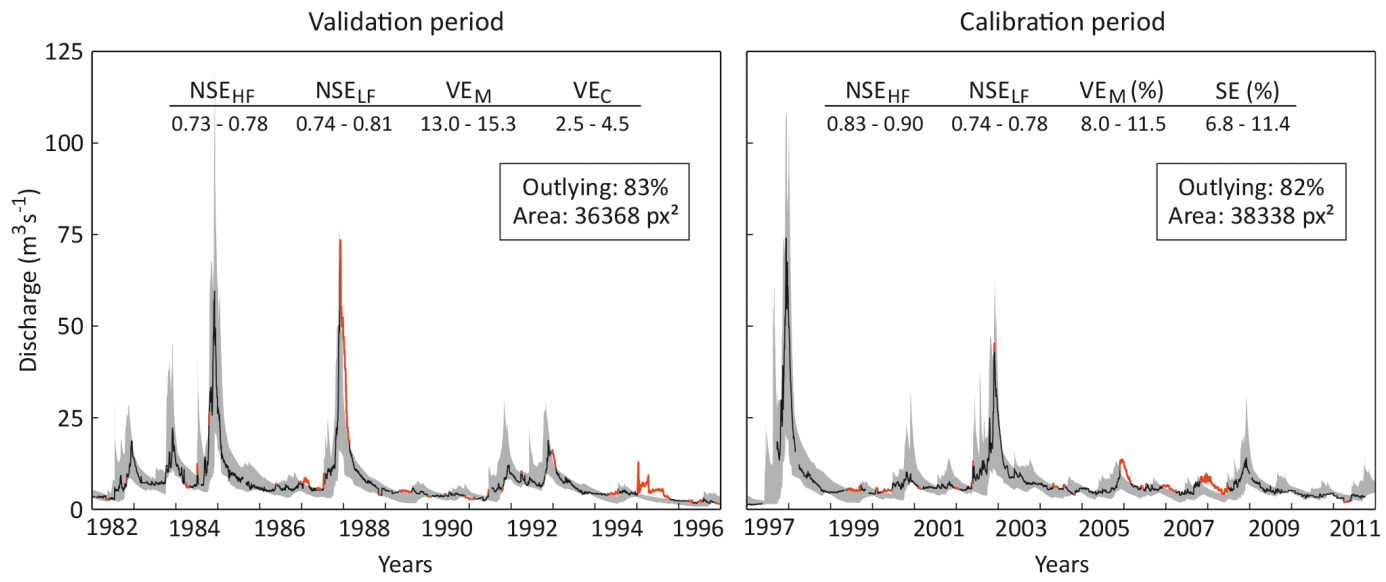

Figure 9. Comparison of observed daily discharge at Rivadavia with the overall uncertainty envelope obtained by combining the Paretoenvelopes of eight model structures. These structures have been selected among the 14 members of cluster 1 in both calibration and validation so as to minimize the uncertainty envelope area (Area, in pixels ${ }^{2}$ ) while holding constant the number of outlying observations (Outlying, in $\%)$. The red parts indicate potential errors in the model structures or observed data.

\subsection{Representation of structural uncertainties}

This section deals with the identification and use of an ensemble of equally acceptable model structures to quantify and represent the uncertainty arising from the system nonidentifiability. Figure 9 shows the overall uncertainty envelope obtained with the eight model structures whose combination minimizes the envelope area in calibration while holding constant the number of outlying observations (see Sect. 3.3). Over $82 \%$ of discharge observations are captured by the envelope in both simulation periods. Interestingly, this number exceeds the best $N_{\text {par }}$ value obtained in calibration with the individual Pareto-envelopes (see Table 4), which shows how necessary it is to consider an ensemble of model structures. In validation, however, a better combination could be identified since several models of cluster 1 display significantly higher $N_{\text {par }}$ values (Table 4 ). On the whole, the comparison of the observed hydrograph with the simulation bounds of the envelope shows a good match of rising limbs and peak discharges in both simulation periods, but a less accurate fit of falling limbs during at least one major (in 19871988) and two minor (in 2005-2006 and 2007-2008) events. The slower recession of the observed hydrograph might indicate a delayed contribution of one or more catchment compartments that cannot be described by any of the modelling options available in the multiple-hypothesis framework.

\section{Discussion and conclusions}

This study aimed at reducing structural uncertainty in the modelling of a semi-arid Andean catchment where lumped conceptual models remain largely under used. To overcome the current lack of information on model adequacy in this catchment, a modular modelling framework (MMF) rely- ing on six model-building decisions was developed to generate 72 competing model structures. Four assessment criteria were then chosen to calibrate and evaluate these models over a 30-year period using the concept of Pareto-optimality. This strategy was designed to characterize both the parameter uncertainty arising from each model's structural deficiencies (i.e. model inadequacy) and the ambiguity associated with the choice of model components (i.e. model nonuniqueness). Finally, a clustering approach was taken to identify natural groupings in the multi-objective space. Overall, the greatest source of uncertainty was found in the connection between runoff generation and runoff transformation components (decisions D and E). However, the results also showed a significant drop in the number of plausible representations of the system. After validation, 14 model structures among the 24 identified in calibration as the bestperforming ones were finally considered as equally acceptable.

\subsection{Improved understanding of hydrological processes}

Interestingly, both rejected and accepted hypotheses appeared closely related to particular types of snowmeltaccounting (decision B), runoff generation (decision C) and runoff transformation (decision D) modelling options, suggesting possible links to some physical features of the catchment. For instance, the frequent occurrence of option $\mathrm{C} 1$ and the absence of option $\mathrm{C} 2$ among the set of best-performing structures indicate that moisture-accounting components may not be essential to the conceptual modelling of this catchment. Most of the land cover is, indeed, dominated by barren to sparsely vegetated exposed rocks, boulders and rubble with poor soil development outside the valleys. This setting may also explain the relatively low values of parameter $K_{C}$ obtained with the black, red and blue so- 
lutions shown in Fig. 7. Likewise, the frequency of options $\mathrm{F} 2 \mathrm{a}$ and F2b in the best-performing cluster suggests that the catchment actually behaves as a "serial" system. The overall organization of fluxes in the catchment, from high elevations toward the valleys and then northward to the outlet, can be conceptualized as a series of two hydraulically connected reservoirs: one standing for the granitic mountain blocks (upstream reservoir) and the other for the alluvial valleys (downstream reservoir). Similar results were also obtained for smaller catchments in Luxembourg characterized by relatively impervious bedrock and lateral water flows (Fenicia et al., 2014). The results also provided some evidence of a strong threshold behaviour at the catchment scale (options F1b, F2b and F3b) compared to the smoother power laws of options F1a, F2a and F3a. However, further research would be needed to track the origin of this behaviour, which might be related at some point to connectivity levels in the fractured and till-mantled areas of the mountain blocks. With regard to snowmelt, the frequent occurrence of option B1c in the best-performing cluster in calibration may indicate a need to account for processes which the degree-day method implemented in option B1a does not fully capture. In semiarid central Andes (29-30 $\left.{ }^{\circ} \mathrm{S}\right)$, small zenith angles and a thin, dry and cloud-free atmosphere during most of the year make incoming short-wave radiation the most important source of seasonal variations in the energy available for melt (e.g. Pellicciotti et al., 2008; Abermann et al., 2013). While this dominant source of energy cannot be accounted for by temperature alone, the seasonal timing of snowmelt is also expected to show a greater year-to-year stability, which may explain the relative success of option B1c when compared to option B1b.

Of course, these hypothesized relationships between some physical characteristics of the catchment and specific modelling options need to be further qualified. Differentiating between physically adequate and purely numerical solutions will always seem somewhat hazardous in the case of lumped conceptual models. For instance, a small number of models among those identified as the best-performing ones also rely on parallel (F1a, F1b) and intermediate (F3b) runoff transformation options. Also, the relative proportions of snowmeltaccounting options B1a, B1b and B1c, appears much more balanced in validation, where no snow error criterion could be applied, than in calibration. Although this was not our objective in this paper, comparative studies including several similar or contrasted catchments would be required to better understand how different model structures relate to different physical settings. Such understanding is of primary importance to the choice of conceptual models in climate change impact studies.

\subsection{Model parsimony}

Another important issue related to model identification is the extent to which the "principle of parsimony" can be applied to differentiate between a large number of model hypotheses. Many authors rightly consider that a maximum of 5 to $6 \mathrm{pa}-$ rameters should be accepted in calibration when using a single objective function. Efstratiadis and Koutsoyiannis (2010) extended this empirical rule to the case of multi-objective schemes by allowing "a ratio of about $1: 5$ to $1: 6$ between the number of criteria and the number of parameters to optimize". For a multi-objective scheme based on four criteria (as in the present study), this leads to consider 20 to 24-parameter models as still being parsimonious. This will certainly seem unreasonable to many modelers because, as Efstratiadis and Koutsoyiannis (2010) also pointed out, the various criteria used are generally not independent of each other. In our case, for instance, the information added by the low-flow criterion may not be so different from that already introduced by the high-flow criterion. By contrast, the snow criterion tends to add new information on the snowrelated parameters. From this perspective, it is noteworthy that most rejected hypotheses among the 24 identified in calibration as members of cluster 1 had more than 11 free parameters, with only one having 9 parameters. The principle of parsimony, however, cannot be used to further discriminate between the remaining 14 best-performing hypotheses. For instance, model no. 54 (12 parameters) performs better than model no. 2 (9 parameters) with respect to the high-flow criterion.

\subsection{Uncertainty quantification}

Eventually, the number of models used to represent structural uncertainty was reduced by searching for which minimal set of models maximized the number of observations covered by the ensemble of Pareto-envelopes. It is important to make clear that model inadequacy and non-uniqueness were evaluated here in non-probabilistic terms. In particular, the Pareto-envelopes derived for each model structure quantify only the uncertainty arising from the trade-offs between competing criteria and do not have a predefined statistical meaning (Engeland et al., 2006). Consequently, the overall simulation bounds shown in Fig. 9 cannot be easily interpreted as "confidence bands". Although discussing the adequacy of non-probabilistic approaches to structural uncertainty was far beyond the scope of this study, it is interesting to analyze the reasons why between 15 and $20 \%$ of the observations remained outside the overall simulated envelope in both calibration and validation. To a large extent, this lack of performance can be attributed either to an insufficient coverage of the hypothesis and objective spaces or to uncertainties in the precipitation and streamflow data that were overlooked in this study.

The choice of Pareto-optimality to characterize structural uncertainty can be criticized for leading to the rejection of many behavioural parameter sets (i.e. being close to, but not part of, the Pareto front) that might have been Pareto-optimal with different performance measures, calibration data or in- 
put errors (e.g. Freer et al., 2003; Beven, 2006). Also, this concept should not be confused with that of equifinality. Both notions agree that it is not possible to identify a single, best solution to the calibration problem and that multiple parameters sets should be retained to give a proper account of model uncertainty. However, the Pareto set of solutions represents the minimum parameter uncertainty that can be achieved when several criteria are considered simultaneously with no a priori preference for one over the others (Gupta et al., 2003). By contrast, two parameter sets are said to be equifinal (in a statistical sense) if they can be regarded as equally acceptable with respect to a given model outcome. For a proper assessment of parameter equifinality, more probabilistic approaches should be taken (Madsen, 2000; Huisman et al., 2010). In the context of multiple-hypothesis testing, a meticulous selection of the assessment criteria is also critical to avoid rejecting some modelling options for the wrong reasons. For instance, the snow error criterion was shown to have a great influence on the identification of snowaccounting components, as much more ambiguity between the various available options was observed during the validation period when this criterion could not be used. Also, like any other multiple-hypothesis framework, the MMF developed in this study suffers from an insufficient coverage of the hypothesis space (Gupta et al., 2012). The parameterization of evapotranspiration, for example, was not considered as an independent model-building decision. Only one formula was applied to calculate potential evapotranspiration and the possibility to retrieve actual evapotranspiration from downstream water stores was not provided. Likewise, the runoff transformation process was described using only two water stores, of which only one was assumed to have a nonlinear behaviour. Future work to improve the conceptual modelling of the Claro River catchment should include the testing of new or refined hypotheses to allow for the use of additional auxiliary data (e.g. observed snow heights or irrigation water use).

\subsection{Data quality issues}

More fundamentally, our ability to discriminate among the competing model hypotheses was constrained by inevitable errors in the input and output data sets. In particular, the comparison of simulated SWE levels and MODIS-based SCA estimates revealed some uncertainty in the estimation of precipitation inputs and confirmed previous results obtained by Favier et al. (2009). Some precipitation events occurring in the early winter may not be captured by the gauging network $(<3200 \mathrm{~m}$ a.s.l.) used for the interpolation of precipitation across the catchment. These errors may add to systematic volume errors caused by wind, wetting and evaporation losses at the gauge level, leading to an overall underestimation of precipitation, as indicated by the rough estimate of the catchment-scale water balance given in Sect. 2. It was also possible to highlight some errors in the streamflow data. The observed streamflow was "naturalized" by simply adding back the estimated historical water abstractions (Sect. 2.2). When applied on a daily basis, this process inevitably adds some uncertainty to streamflow values because a significant part of surface-water abstractions actually return to the river system within a few days due to conveyance and field losses. In general, ignoring these return flows would lead to overestimating daily natural flows. In this paper, however, the actual water withdrawals were not known with precision but only as percentages of the nominal water rights these percentages being fixed on a monthly basis by the authorities to account for variations in water availability. The combined impact of streamflow and precipitation errors on the assessment of structural uncertainty thus remained unknown. Further research is currently underway to integrate the effects of water abstractions and crop water use in the hydrological modelling process (Hublart et al., 2015; see also Kiptala et al., 2014 for another approach). From a multiplehypothesis perspective, the modelling of irrigation water use should be regarded as a testable model component in its own right.

Acknowledgements. The authors are very grateful to the Centro de Estudios Avanzados en Zonas Áridas (CEAZA) for its essential logistic support during the field missions and to Gustavo Freixas from the Dirección General de Agua (Chile) for providing the necessary streamflow data. The authors also thank S. Lhermitte, D. López and S. MacDonell for providing the MODIS data used in this study and S. Gascoin for informal advice and much useful discussion. Moreover, the authors thank the two anonymous reviewers for their interest in this work and for their useful comments that helped to improve the article.

Edited by: T. Kjeldsen

\section{References}

Abermann, J., Kinnard, C., and MacDonell, S.: Albedo variations and the impact of clouds on glaciers in the Chilean semi-arid Andes, J. Glaciol., 60, 183-191, 2013.

Bekele, E. G. and Nicklow, J. W.: Multi-objective automatic calibration of SWAT using NSGA-II, J. Hydrol., 341, 165-176, 2007.

Beven, K.: Prophecy, reality and uncertainty in distributed hydrological modelling, Adv. Water Resour., 16, 41-51, 1993.

Beven, K.: A Manifesto for the Equifinality Thesis, J. Hydrol., 320, 18-36, 2006.

Bezdek, J. C., Ehrlich, R., and Full, W.: FCM: The fuzzy c-means clustering algorithm, Comput. Geosci., 10, 191-203, 1983.

Birkel, C., Tetzlaff, D., Dunn, S. M., and Soulsby, C.: Towards a simple dynamic process conceptualization in rainfall-runoff models using multi-criteria calibration and tracers in temperate, upland catchments, Hydrol. Process., 24, 260-275, 2010. Blöschl, G. and A. Montanari: Climate change impacts-throwing the dice?, Hydrol. Process., 24, 374-381, 2010.

Blöschl, G. and Montanari, A.: Climate change impacts - throwing the dice?, Hydrol. Process., 24, 374-381, 2010. 
Boyle, D. P., Gupta, H. V., and Sorooshian, S.: Toward improved calibration of hydrologic models: Combining the strengths of manual and automatic methods, Water Resour. Res., 36, 36633674, 2000.

Buytaert, W. and K. Beven: Models as multiple working hypotheses: hydrological simulation of tropical alpine wetlands, Hydrol. Process., 25, 1784-1799, 2011.

Capell, R., Tetzlaff, D., and Soulsby, C.: Can time domain and source area tracers reduce uncertainty in rainfall-runoff models in larger heterogeneous catchments?, Water Resour. Res., 48, W09544, doi:10.1029/2011WR011543, 2012.

Caviedes, C. N. and Paskoff, R.: Quaternary glaciations in the Andes of north-central Chile, J. Glaciol., 14, 155-169, 1975.

Centro del Agua para Zonas Áridas y semiáridas de América Latina y el Caribe (CAZALAC): Aplicación de metodologías para determinar la eficiencia de uso del agua - Estudio de caso en la Región de Coquimbo. Informe Técnico, Gobierno Regional, Santiago (Chile), 2006.

Chiu, S.: Fuzzy model identification based on cluster estimation, J. Intell. Fuzzy Syst., 2, 267-278, 1994.

Clark, M. P., Slater, A. G., Barrett, A. P., Hay, L. E., McCabe, G. J., Rajagopalan, B., and Leavesley, G. H.: Assimilation of snow covered area information into hydrologic and landsurface models, Adv. Water Resour., 29, 1209-1221, 2006.

Clark, M. P., Slater, A. G., Rupp, D. E., Woods, R. A., Vrugt, J. A., Gupta, H. V., Wagener, T., and Hay, L. E.: Framework for Understanding Structural Errors (FUSE): A modular framework to diagnose differences between hydrological models, Water Resour. Res., 44, W00B02, doi:10.1029/2007WR006735, 2008.

Clark, M., Hreinsson, E. O., Martinez, G., Tait, A., Slater, A., Hendrikx, J., Owens, I., Gupta, H., Schmidt, J., and Woods, R.: Simulations of seasonal snow for the South Island, New Zealand, J. Hydrol., 48, 41-58, 2009.

Clark, M. P., Kavetski, D., and Fenicia, F.: Pursuing the method of multiple working hypotheses for hydrological modelling, Water Resour. Res., 47, W09301, doi:10.1029/2010WR009827, 2011.

Collet, L., Ruelland, D., Borrell-Estupina, V., Dezetter, A., and Servat, E.: Integrated modelling to assess long-term water supply capacity of a meso-scale Mediterranean catchment, Sci. Total Environ., 461/462, 528-540, 2013.

Coxon, G., Freer, J., Wagener, T., Odoni, N. A., and Clark, M. P.: Diagnostic evaluation of multiple hypotheses of hydrological behaviour in a limits-of-acceptability framework for 24 UK catchments, Hydrol. Process., 28, 6135-6150, doi:10.1002/hyp.10096, 2013.

De Vos, N. J. and Rientjes, T. H. M.: Multi-objective performance comparison of an artificial neural network and a conceptual rainfall-runoff model, Hydrolog. Sci. J., 52, 397-413, 2007.

Deb, K., Pratap. A, Agarwal, S., and Meyarivan, T.: A fast and elitist multiobjective genetic algorithm: NSGA-II, IEEE T. Evolut. Comput., 6, 181-197, 2002.

Dooge, J.: Looking for hydrologic laws, Water Resour. Res., 22, 46S-58S, doi:10.1029/WR022i09Sp0046S, 1986.

Dooge, J.: Searching for Simplicity in Hydrology, Surv. Geophys., 18, 511-534, 1997.

Efstratiadis, A. and Koutsoyiannis, D.: One decade of multiobjective calibration approaches in hydrological modelling: a review, Hydrolog. Sci. J., 55, 58-78, 2010.
Ehret, U., Gupta, H. V., Sivapalan, M., Weijs, S. V., Schymanski, S. J., Blöschl, G., Gelfan, A. N., Harman, C., Kleidon, A., Bogaard, T. A., Wang, D., Wagener, T., Scherer, U., Zehe, E., Bierkens, M. F. P., Di Baldassarre, G., Parajka, J., van Beek, L. P. H., van Griensven, A., Westhoff, M. C., and Winsemius, H. C.: Advancing catchment hydrology to deal with predictions under change, Hydrol. Earth Syst. Sci., 18, 649-671, doi:10.5194/hess-18-6492014, 2014.

Engeland, K., Braud, I., Gottschalk, L., and Leblois, E.: Multiobjective regional modelling, J. Hydrol., 327, 339-351, 2006.

Favier, V., Falvey, M., Rabatel, A., Praderio, E., and López, D.: Interpreting discrepancies between discharge and precipitation in high-altitude area of Chile's Norte Chico region (26-32 ${ }^{\circ} \mathrm{S}$ ), Water Resour. Res., 45, W02424, doi:10.1029/2008WR006802, 2009.

Fenicia, F., McDonnell, J. J., and Savenije, H. H. G.: Learning from model improvement: On the contribution of complementary data to process understanding, Water Resour. Res., 44, W06419, doi:10.1029/2007WR006386, 2008a.

Fenicia, F., Savenije, H. H. G., Matgen, P., and Pfister, L.: Understanding catchment behavior through stepwise model concept improvement, Water Resour. Res., 44, W01402, doi:10.1029/2006WR005563, 2008b.

Fenicia, F., Kavetski, D., and Savenije, H. H. G.: Elements of a flexible approach for conceptual hydrological modelling: 1. Motivation and theoretical development, Water Resour. Res., 47, W11510, doi:10.1029/2010WR010174, 2011.

Fenicia, F., Kavetski, D., Savenije, H. H. G., Clark, M. P., Schoups, G., Pfister, L., and Freer, J.: Catchment properties, function, and conceptual model representation: is there a correspondence?, Hydrol. Process., 28, 2451-2467, 2014.

Freer, J., Beven, K., and Peters, N.: Multivariate Seasonal Period Model Rejection Within the Generalised Likelihood Uncertainty Estimation Procedure, in Calibration of Watershed Models, edited by: Duan, Q., Gupta, H. V., Sorooshian, S., Rousseau, A. N., and Turcotte, R., Am. Geophys. Union, Washington, DC, 69-87, 2003.

Gupta, H. V., Sorooshian, S., and Yapo, P. O.: Toward improved calibration of hydrologic models: Multiple and noncommensurable measures of information, Water Resour. Res., 34, 751-763, 1998.

Gupta, H. V., Bastidas, L. A., Vrugt, J. A., and Sorooshian, S.: Multiple criteria global optimization for watershed model calibration, Water Sci. Appl., 6, 125-132, 2003.

Gupta, H. V., Clark, M. P., Vrugt, J. A., Abramowitz, G., and Ye, M.: Towards a comprehensive assessment of model structural adequacy, Water Resour. Res., 48, W08301, doi:10.1029/2011WR011044, 2012.

Hock, R.: Temperature index melt modelling in mountain areas, J. Hydrol., 282, 104-115, 2003.

Hublart, P., Ruelland, D., Dezetter, A., and Jourde, H.: Modelling current and future trends in water availability for agriculture on a semi-arid and mountainous Chilean catchment, in: Cold and Mountain Region Hydrological Systems Under Climate Change: Towards Improved Projections, IAHS-AISH P., 360, 26-32, 2013.

Hublart, P., Ruelland, D., Dezetter, A., and Jourde, H.: Assessing the capacity to meet irrigation water needs for viticulture under climate variability in the Chilean Andes, in: Hydrology in a Changing World: Environmental and Human Dimensions, Proc. 
7th FRIEND Int. Conf., Montpellier, France, 24-28 February 2014, IAHS-AISH P., 363, 209-214, 2014.

Hublart, P., Ruelland, D., García de Cortázar Atauri, I., and Ibacache, A.: Assessing the reliability of conceptual hydrological modelling in a cultivated, drought-prone catchment of the Chilean Andes, in: Hydrologic Non-Stationarity and Extrapolating Models to Predict the Future, IAHS-AISH P, 92, 1-7, 2015.

Huisman, J. A., Rings, J., Vrugt, J. A., Sorg, J., Vereecken, H.: Hydraulic properties of a model dike from coupled Bayesian and multi-criteria hydrogeophysical inversion, J. Hydrol., 380, 6273, 2010.

IPCC: Full Report: the Physical Science Basis, in: Contribution of Working Group I to the Fifth Assessment Report of the Intergovernmental Panel on Climate Change, Climate Change 2013, edited by: Stocker, T. F., Qin, D., Plattner, G.-K., Tignor, M., Allen, S. K., Boschung, J., Nauels, A., Xia, Y., Bex, V., and Midgley, P. M., Cambridge University Press, Cambridge, UK and New York, NY, USA, 1261-1264, 2013.

Jakeman, A. J. and Hornberger, G. M.: How much complexity is warranted in a rainfall-runoff model?, Water Resour. Res., 29, 2637-2649, 1993.

Jakeman, A. J. and Letcher, R. A.: Integrated assessment and modelling: features, principles and examples for catchment management, Environ. Modell. Softw., 18, 491-501, 2003.

Jothityangkoon, C., Sivapalan, M., and Farmer, D. L.: Process controls of water balance variability in a large semi-arid catchment: downward approach to hydrological model development, J. Hydrol., 254, 174-198, 2001.

Jourde, H., Rochette, R., Blanc, M., Brisset, N., Ruelland, D., Freixas, G., and Oyarzun, R. : Relative contribution of groundwater and surface water fluxes in response to climate variability of a mountainous catchment in the Chilean Andes, in: Cold Regions Hydrology in a Changing Climate, IAHS-AISH P., 346, 180-188, 2011.

Kalthoff, N., Fiebig-Wittmaack, M., Meißner, C., Kohler, M., Uriarte, M., Bischoff-Gauß, I., and Gonzales, E.: The energy balance, evapo-transpiration and nocturnal dew deposition of an arid valley in the Andes, J. Arid Environ., 65, 420-443, 2006.

Kavetski, D. and Fenicia, F.: Elements of a flexible approach for conceptual hydrological modelling: 2. Application and experimental insights, Water Resour. Res., 47, W11511, doi:10.1029/2011WR010748, 2011.

Kavetski, D. and Kuczera, G.: Model smoothing strategies to remove microscale discontinuities and spurious secondary optima in objective functions in hydrological calibration, Water Resour. Res., 43, W03411, doi:10.1029/2006WR005195, 2007.

Khu, S. T., and Madsen, H.: Multiobjective calibration with Pareto preference ordering: An application to rainfallrunoff model calibration, Water Resour. Res., 41, W03004, doi:10.1029/2004WR003041, 2005.

Kiptala, J. K., Mul, M. L., Mohamed, Y. A. and van der Zaag, P.: Modelling stream flow and quantifying blue water using a modified STREAM model for a heterogeneous, highly utilized and data-scarce river basin in Africa, Hydrol. Earth Syst. Sci., 18, 2287-2303, 2014,

http://www.hydrol-earth-syst-sci.net/18/2287/2014/.

Kirchner, J. W.: Getting the right answers for the right reasons: Linking measurements, analyses, and models to advance the science of hydrology, Water Resour. Res., 42, WR004362, doi:10.1029/2005WR004362, 2006.

Kokkonen, T. S. and Jakeman, A. J.: A comparison of metric and conceptual approaches in rainfall-runoff modelling and its implications, Water Resour. Res., 37, 2345-2352, 2001.

Krueger, T., Freer, J., Quinton, J. N., Macleod, C. J. A., Bilotta, G. S., Brazier, R. E., Butler, P., and Haygarth, P. M.: Ensemble evaluation of hydrological model hypotheses, Water Resour. Res., 46, W07516, doi:10.1029/2009WR007845, 2010.

Lee, G., Tachikawa, Y., and Takara, K.: Comparison of model structural uncertainty using a multi-objective optimization method, Hydrol. Process., 25, 2642-2653, 2011.

MacDonell, S., Kinnard, C., Mölg, T., Nicholson, L., and Abermann, J.: Meteorological drivers of ablation processes on a cold glacier in the semiarid Andes of Chile, The Cryosphere, 7, 18331870, doi:10.5194/tc-7-1513-2013, 2013.

Madsen, H.: Automatic calibration of a conceptual rainfall-runoff model using multiple objectives, J. Hydrol., 235, 276-288, 2000.

McDonnell, J. J., Sivapalan, M., Vaché, K., Dunn, S., Grant, G., Haggerty, R., Hinz, C., Hooper, R., Kirchner, J., Roderick, M. L., Selker, J., and Weiler, M.: Moving beyond heterogeneity and process complexity: A new vision for watershed hydrology, Water Resour. Res., 43, W07301, doi:10.1029/2006WR005467, 2007.

McMillan, H.: Effect of spatial variability and seasonality in soil moisture on drainage thresholds and fluxes in a conceptual hydrological model, Hydrol. Process., 26, 2838-2844, 2012a.

McMillan, H., Tetzlaff, D., Clark, M., and Soulsby, C.: Do timevariable tracers aid the evaluation of hydrological model structure? A multimodel approach, Water Resour. Res., 48, W05501, doi:10.1029/2011WR011688, 2012b.

Michaud, J. and Sorooshian, S.: Comparison of simple versus complex distributed runoff models on a semi-arid watershed, Water Resour. Res., 30, 593-605, 1994.

Milano, M., Ruelland, D., Dezetter, A., Fabre, J., Ardoin-Bardin, S., and Servat, E.: Modelling the current and future capacity of water resources to meet water demands in the Ebro basin, J. Hydrol., 500, 114-126, 2013.

Minville, M., Brissette, F., and Leconte, R.: Uncertainty of the impact of climate change on the hydrology of a nordic watershed, J. Hydrol., 358, 70-83, 2008.

Montecinos, A. and Aceituno, P.: Seasonality of the ENSO-Related Rainfall Variability in Central Chile and Associated Circulation Anomalies, J. Climate, 16, 281-296, 2003.

Moore, R. J.: The PDM rainfall-runoff model, Hydrol. Earth Syst. Sci., 11, 483-499, doi:10.5194/hess-11-483-2007, 2007.

Oudin, L., Hervieu, F., Michel, C., Perrin, C., Andréassian, V., Anctil, F., and Loumagne, C.: Which potential evapotranspiration input for a lumped rainfall-runoff model?: Part 2-Towards a simple and efficient potential evapotranspiration model for rainfallrunoff modelling, J. Hydrol., 303, 290-306, 2005.

Parajka, J. and Blöschl, G.: The value of MODIS snow cover data in validating and calibrating conceptual hydrologic models, J. Hydrol., 358, 240-258, 2008.

Pellicciotti, F., Helbing, J., Rivera, A., Favier, V., Corripio, J., Araos, J., Sicart, J.-E. and Carenzo, M.: A study of the energy balance and melt regime on Juncal Norte Glacier, semi-arid Andes of central Chile, using melt models of different complexity, Hydrol. Process., 22, 3980-3997, 2008. 
Perrin, C., Michel, C., and Andréassian, V.: Improvement of a parsimonious model for streamflow simulation, J. Hydrol., 279, 275289, 2003.

Pourrier, J., Jourde, H., Kinnard, C., Gascoin, S., and Monnier, S.: Glacier meltwater flow paths and storage in a geomorphologically complex glacial foreland: The case of the Tapado glacier, dry Andes of Chile (30 S), J. Hydrol., 519, 1068-1083, 2014.

Quintana, J. M. and Aceituno, P.: Changes in the rainfall regime along the extratropical west coast of South America (Chile): 30 $43^{\circ} \mathrm{S}$, Atmósfera, 25, 1-22, 2012.

Refsgaard, J. C. and Knudsen, J.: Operational validation and intercomparison of different types of hydrological models, Water Resour. Res., 32, 2189-2202, 1996.

Ruelland, D., Brisset, N., Jourde, H., and Oyarzun, R.: Modelling the impact of climatic variability on the groundwater and surface flows from a mountainous catchment in the Chilean Andes, in: Cold Regions Hydrology in a Changing Climate, IAHS-AISH P., 346, 171-179, 2011.

Ruelland, D., Ardoin-Bardin, S., Collet, L., and Roucou, P.: Simulating future trends in hydrological regime of a large SudanoSahelian catchment under climate change, J. Hydrol., 424/425, 207-216, 2012.

Ruelland, D., Dezetter, A., and Hublart, P.: Sensitivity analysis of hydrological modelling to climate forcing in a semi-arid mountainous catchment, in: Hydrology in a Changing World: Environmental and Human Dimensions, Proc. 7th FRIEND Int. Conf., Montpellier, France, 24-28 February 2014, IAHS-AISH P., 363, 145-150, 2014.

Savenije, H. H. G.: HESS Opinions "The art of hydrology", Hydrol. Earth Syst. Sci., 13, 157-161, doi:10.5194/hess-13-1572009, 2009.

Schaefli, B., Harman, C. J., Sivapalan, M., and Schymanski, S. J.: HESS Opinions: Hydrologic predictions in a changing environment: behavioral modelling, Hydrol. Earth Syst. Sci., 15, 635646, doi:10.5194/hess-15-635-2011, 2011.

Schreider, S., Whetton, P. H., Jakeman, A. J., and Pittock, A. B.: Runoff modelling for snow-affected catchments in the australian alpine region, eastern Victoria, J. Hydrol., 200, 1-23, 1997.

Seibert, J.: Multi-criteria calibration of a conceptual runoff model using a genetic algorithm, Hydrol. Earth Syst. Sci., 4, 215-224, doi:10.5194/hess-4-215-2000, 2000.

Seibert, J. and McDonnell, J. J.: On the dialog between experimentalist and modeler in catchment hydrology: Use of soft data for multicriteria model calibration, Water Resour. Res., 38, W01241, doi:10.1029/2001WR000978, 2002.

Seibert, J. and Vis, M. J. P.: Teaching hydrological modeling with a user-friendly catchment-runoff-model software package, Hydrol. Earth Syst. Sci., 16, 3315-3325, doi:10.5194/hess-16-33152012, 2012.

Shafii, M. and De Smedt, F.: Multi-objective calibration of a distributed hydrological model (WetSpa) using a genetic algorithm, Hydrol. Earth Syst. Sci., 13, 2137-2149, doi:10.5194/hess-132137-2009, 2009.

Sivapalan, M., Blöschl, G., Zhang, L., and Vertessy, R.: Downward approach to hydrological prediction, Hydrol. Process., 17, 2101$2111,2003$.
Sivapalan, M.: Pattern, process and function: elements of a unified theory of hydrology at the catchment scale, in: Encyclopedia of Hydrological Sciences, edited by: Anderson, M. G., vol. 1, Wiley, Chichester, 193-220, 2005.

Smith, T. J. and Marshall, L. A.: Exploring uncertainty and model predictive performance concepts via a modular snowmelt-runoff modelling framework, Environ. Modell. Softw., 25, 691-701, 2010 .

Son, K. and Sivapalan, M.: Improving model structure and reducing parameter uncertainty in conceptual water balance models through the use of auxiliary data, Water Resour. Res., 43, W01415, doi:10.1029/2006WR005032, 2007.

Souvignet, M: Climate Change Impacts on Water Availability in the Semiarid Elqui Valley, Chile, Ph.D. thesis, Cologne University of Applied Sciences, Institute for Technology in the Tropics, 110 pp., 2007.

Souvignet, M., Hartmut, G., Lars, R., Kretschmer, N., and Oyarzún, R.: Statistical downscaling of precipitation and temperature in north-central Chile: an assessment of possible climate change impacts in an arid Andean watershed, Hydrol. Sci. J., 55, 41-57, 2010.

Squeo, F. A., Veit, H., Arancio, G., Gutiérrez, J. R., Arroyo, M. T. K., and Olivares, N.: Spatial heterogeneity of high mountain vegetation in the Andean desert zone of Chile ( $\left.30^{\circ} \mathrm{S}\right)$, Mt. Res. Dev., 13, 203-209, 1993.

Staudinger, M., Stahl, K., Seibert, J., Clark, M. P., and Tallaksen, L. M.: Comparison of hydrological model structures based on recession and low flow simulations, Hydrol. Earth Syst. Sci., 15, 3447-3459, doi:10.5194/hess-15-3447-2011, 2011.

Strauch, G., Oyarzun, J., Fiebig-Wittmaack, M., González, E., and Weise, S. M.: Contributions of the different water sources to the Elqui river runoff (northern Chile) evaluated by H/O isotopes, Isot. Environ. Health S., 42, 303-322, 2006.

Verbist, K., Robertson, A. W., Cornelis, W. M., and Gabriels, D.: Seasonal predictability of daily rainfall characteristics in central northern Chile for dry-land management, J. Appl. Meteorol. Clim., 49, 1938-1955, 2010.

Vicuña, S., Garreaud, R., and McPhee, J.: Climate change impacts on the hydrology of a snowmelt driven basin in semiarid Chile, Clim. Change, 105, 469-488, 2011.

Wagener, T., Lees, M. J., and Wheater, H. S.: A toolkit for the development and applications of parsimonious hydrological models, in: Mathematical Models of Large Watershed Hydrology, vol. 1, edited by: Singh, V. P. and Frevert, D., Water Resources Publishers, Highland Ranch, CO, 87-136, 2002.

Wainwright, J. and Mulligan, M. (Eds.): Environmental modelling - Finding simplicity in complexity. Chichester, John Wiley \& Sons, Ltd., 2004.

$\mathrm{Xu}$, C.-Y. and Singh, V. P.: Review on regional water resources assessment models under stationary and changing climate, Water Resour. Manage., 18, 591-612, 2004.

Young, G., Zavala, H., Wandel, J., Smit, B., Salas, S., Jimenez, E., Fiebig, M., Espinoza, R., Diaz, H., and Cepeda, J.: Vulnerability and adaptation in a dryland community of the Elqui Valley, Chile, Clim. Change, 98, 245-276, 2010. 